\title{
Aerosol forcing based on CAM5 and AM3 meteorological fields
}

\author{
C. Zhou ${ }^{1}$, J. E. Penner ${ }^{1}$, Y. Ming ${ }^{2}$, and X. L. Huang ${ }^{1}$ \\ ${ }^{1}$ Department of Atmospheric, Oceanic, and Space Sciences, University of Michigan, Ann Arbor, Michigan, USA \\ ${ }^{2}$ Geophysical Fluid Dynamics Laboratory/NOAA, Princeton, New Jersey, USA \\ Correspondence to: C. Zhou (zhouc@umich.edu)
}

Received: 10 March 2012 - Published in Atmos. Chem. Phys. Discuss.: 25 April 2012

Revised: 19 September 2012 - Accepted: 2 October 2012 - Published: 24 October 2012

\begin{abstract}
We use a single aerosol model to explore the effects of the differing meteorological fields from the NCAR CAM5 and GFDL AM3 models. We simulate the global distributions of sulfate, black carbon, organic matter, dust and sea salt using the University of Michigan IMPACT model and use these fields to calculate aerosol direct and indirect forcing, thereby isolating the impacts of the differing meteorological fields.
\end{abstract}

Over all, the IMPACT-AM3 model predicts larger burdens and longer aerosol lifetimes than the IMPACT-CAM5 model. However, the IMPACT-CAM5 simulations transport more black carbon to the polar regions and more dust from Asia towards North America. These differences can mainly be attributed to differences in: (1) the vertical cloud mass flux and large-scale precipitation fields which determine the wet deposition of aerosols; (2) the in-cloud liquid water content and the cloud coverage which determine the wet aqueous phase production of sulfate. The burden, lifetime and global distribution, especially black carbon in polar regions, are strongly affected by choice of the parameters used for wet deposition.

The total annual mean aerosol optical depth (AOD) at $550 \mathrm{~nm}$ ranges from 0.087 to 0.122 for the IMPACT-AM3 model and from 0.138 to 0.186 for the IMPACT-CAM5 model (range is due to different parameters used for wet deposition). Even though IMPACT-CAM5 has smaller aerosol burdens, its AOD is larger due to the much higher relative humidity in CAM5 which leads to more hygroscopic growth. The corresponding global annual average anthropogenic and all-sky aerosol direct forcing at the top of the atmosphere ranges from $-0.25 \mathrm{~W} \mathrm{~m}^{-2}$ to $-0.30 \mathrm{~W} \mathrm{~m}^{-2}$ for IMPACT-AM 3 and from $-0.48 \mathrm{~W} \mathrm{~m}^{-2}$ to $-0.64 \mathrm{~W} \mathrm{~m}^{-2}$ for IMPACT-CAM5. The global annual average anthropogenic 1st aerosol indirect effect at the top of the atmosphere ranges from $-1.26 \mathrm{~W} \mathrm{~m}^{-2}$ to $-1.44 \mathrm{~W} \mathrm{~m}^{-2}$ for IMPACT-AM3 and from $-1.74 \mathrm{~W} \mathrm{~m}^{-2}$ to $-1.77 \mathrm{~W} \mathrm{~m}^{-2}$ for IMPACT-CAM5.

\section{Introduction}

The effects of different meteorological fields from different climate models has been explored within the atmospheric aerosol and climate modeling community through both model intercomparisons that use a single aerosol model with different meteorological driving fields (e.g. Liu et al., 2007; Zhang et al., 2010) and through coupled aerosol/climate model intercomparisons where a range of different models are compared (e.g. Penner et al., 2002, 2006; Kinne et al., 2006; Schulz et al., 2006; Textor et al., 2006; 2007; Shindell et al., 2008). The latter types of comparisons, unfortunately, combine differences because of diverse treatments of atmospheric aerosol processes (Textor et al., 2006, 2007) and because of varying meteorological fields. The burden and lifetimes of aerosols differ significantly among these models, but it is very difficult to identify which meteorological variables cause the differences or whether they are caused by the aerosol treatments.

In present paper, we follow the approach first studied in Liu et al. (2007) where a single aerosol model, the University of Michigan IMPACT aerosol model, is driven by two sets of meteorological fields: one from the NCAR Community Atmosphere Model (version 5) and one from the GFDL AM3 model. Both models are participating the Coupled Model Intercomparison Project Phase 5 (CMIP5).We analyze the differences and uncertainties of aerosol simulations (for sulfate, organic matter, black carbon, dust and sea salt) solely caused by differing meteorology. The IMPACT aerosol model uses the same emission fluxes, the same chemical scheme (e.g., for sulfur chemistry), and the same physical treatments (e.g., for dry and wet deposition, for vertical diffusion and convective transport of trace species) when driven by these two sets of meteorological fields. In addition, the aerosol optical depth, direct radiative forcing, and first aerosol indirect 
radiative forcing are calculated using the same aerosol optical properties and cloud droplet nucleation scheme. Thus, the model estimated direct and indirect forcing differences are solely due to the meteorology used in the calculations. The model is described in Sect. 2. Comparison of the meteorological fields is presented in Sect. 3. Model simulated aerosol spatial distributions, budgets, aerosol optical depth, aerosol direct forcing, and aerosol direct/indirect forcings are presented in Sect. 4. Section 5 presents a summary and a short discussion.

\section{Model description and set-up of simulations}

\subsection{IMPACT aerosol model}

The 3-mode offline version of the University of Michigan IMPACT aerosol model was used in this study (Liu et al., 2005; Wang et al., 2009). It predicts both the mass and number of pure sulfate aerosol in 3 modes: the nucleation mode with particle radius less than $5 \mathrm{~nm}$, the Aitken mode with dry particle radius between $5 \mathrm{~nm}$ and $0.05 \mu \mathrm{m}$ and the accumulation mode with particle radius larger than $0.05 \mu \mathrm{m}$. Pure sulfate aerosol mixes with primary emitted nonsulfate aerosols: organic matter (OM), black carbon (BC), dust and sea salt through condensation and coagulation. Dust and sea salt are predicted in four bins with radii varying from $0.05-0.63 \mu \mathrm{m}$, $0.63-1.26 \mu \mathrm{m}, 1.26-2.5 \mu \mathrm{m}$, and $2.5-10 \mu \mathrm{m}$, while $\mathrm{OM}$ and $\mathrm{BC}$ are represented by one single submicron bin. A predefined, fixed size distribution represented by one or a superposition of two or three lognormal size distributions is used for each size bin (see Table 1 of Wang et al., 2009).

Present day (PD) and preindustrial (PI) emissions of aerosol species and their precursors are summarized in Table 1 . Direct emission of internally mixed particles may be possible but is not considered in our model. We assumed that $2 \%$ of fossil fuel sulfur emissions occur as primary sulfate aerosol to account for fast conversion of $\mathrm{SO}_{2}$ to sulfate particles in combustion plumes. Details were described in Wang et al. (2009). Sea salt emissions are calculated online based on the meteorological fields following the parameterization by Martensson et al. (2003) for aerosols with geometric diameter $<2.8 \mu \mathrm{m}$ and by Monahan et al. (1986) for aerosols with a geometric diameter $>2.8 \mu \mathrm{m}$.

The wet scavenging scheme in IMPACT follows the Harvard wet scavenging model (Giorgi and Chameides, 1986; Balkanski et al., 1993; Mari et al., 2000; Liu et al., 2001). Two types of scavenging are implemented: (1) scavenging in wet convective updrafts, and (2) first-order rainout and washout by the large scale precipitation. For the first type, instead of using the convective precipitation directly, wet scavenging is implemented in the vertical transport process using the vertical cloud mass flux, aerosol loss rate $(k)$ and updraft velocity $(w)$ (Liu et al., 2001; description of the algorithm is available in full from http://acmg.seas.harvard.edu/
Table 1. Emissions of aerosol and precursors in present day (PD) and pre-industrial (1870) (PI) conditions ( $\mathrm{Tg} \mathrm{yr}^{-1}$ or $\mathrm{Tg} \mathrm{S} \mathrm{yr}^{-1}$ ).

\begin{tabular}{llll}
\hline & PD & PI & Reference \\
\hline DMS & 26.1 & 26.1 & Kettle and Andreae (2000) \\
$\begin{array}{l}\text { Dust } \\
\mathrm{SO}_{2}\end{array}$ & 2356 & 2356 & Ginoux et al. (2001) \\
Volcanic & 9.57 & 9.57 & Andres and Kasgnoc (1998) \\
Fossil fuel & 61.2 & 1.51 & Smith et al. (2001, 2004) \\
OM & & & \\
Natural sources & 14.5 & 14.5 & Penner et al. (2001) \\
Fossil fuel & 15.67 & 5.09 & Ito and Penner (2005) \\
$\begin{array}{l}\text { Biomass burning } \\
\text { BC }\end{array}$ & 47.39 & 17.91 & Ito and Penner (2005) \\
Fossil fuel & 5.80 & 0.77 & Ito and Penner (2005) \\
Biomass burning & 4.71 & 1.75 & Ito and Penner (2005) \\
\hline
\end{tabular}

geos/wiki_docs/deposition/wetdep.jacob_etal_2000.pdf). For a convective column of thickness $\Delta z$, the fraction $f$ of aerosol tracer scavenged by convective precipitation in the updraft is $f=1-\exp (-k \Delta z / w)$. Then the total amount of aerosols scavenged is $f$ times the amount of aerosol carried by the convective cloud mass. In this scheme tracers are prevented from being transported to the top of the convective updrafts and then dispersed on the grid scale. However, convective precipitation is not being used directly. The scavenging efficiency is also sensitive to the choice of the loss rate $(k)$ and the assumed updraft velocity $(w)$. For the second type, i.e. large scale precipition, the 3-D precipitation field is first reconstructed using the change of specific humidity. The fractional area of the gridbox where the precipitation forms is $Q /(k(\mathrm{~L}+\mathrm{W})+\mathrm{Q})$, where $Q$ is the change of the specific humidity due to the large scale precipitation (provided by the GCMs), $\mathrm{L}+\mathrm{W}\left(\mathrm{cm}^{3} \mathrm{~m}^{-3}\right)$ is the assumed condensed water content (liquid + ice) within the precipitating cloud and $k$ $\left(=10^{-4} \mathrm{~s}^{-1}\right)$ is the rainout rate of condensed water. The $Q$ in the denominator is added to make sure the precipitating fraction is less than 1. Smaller $\mathrm{L}+\mathrm{W}$ means that a larger fraction of area experiences precipitation. To test the sensitivity of the aerosol burden and lifetime to these assumptions for large scale precipitation, two values for $\mathrm{L}+\mathrm{W}\left(0.5 \mathrm{~cm}^{3} \mathrm{~m}^{-3}\right.$ and $1.5 \mathrm{~cm}^{3} \mathrm{~m}^{-3}$ ), which were used in Liu et al. (2001) and are consistent with observed range (see Fig. 6a in Bower et al., 1994), are also used in the present paper.

\subsection{NCAR CAM5 and GFDL AM3}

Version 5.0 of the Community Atmosphere Model (CAM5) is the atmospheric component of the Community Earth System Model (CESM) developed primarily at the National Center for Atmospheric Research (NCAR) (Liu et al., 2012). The default stand-alone CAM with prescribed climatological sea surface temperature/ice and CAM5 physics was used. AM3 is the atmospheric component of the coupled general circulation model (CM3) developed in NOAA Geophysical Fluid 
Table 2. Description of cases.

\begin{tabular}{ll}
\hline Case names & Descriptions \\
\hline CAM5-base & $\begin{array}{l}\text { Default set-up of CAM5, the } \\
\text { "FCM5" compset of CESM 1.0.2 }\end{array}$ \\
AM3-base & $\begin{array}{l}\text { Default set-up of AM3 } \\
\text { IMPACT driven by the meteorological fields from }\end{array}$ \\
C2 & $\begin{array}{l}\text { CAM5-base with } \mathrm{L}+\mathrm{W}=0.5 \mathrm{~cm}^{3} \mathrm{~m}^{-3} \\
\text { IMPACT driven by the meteorological fields from }\end{array}$ \\
A1 & $\begin{array}{l}\text { CAM3-base with } \mathrm{L}+\mathrm{W}=1.5 \mathrm{~cm}^{3} \mathrm{~m}^{-3} \\
\text { IMPACT driven by the meteorological fields from }\end{array}$ \\
A2 & $\begin{array}{l}\text { AM3-base with } \mathrm{L}+\mathrm{W}=0.5 \mathrm{~cm}^{3} \mathrm{~m}^{-3} \\
\text { IMPACT driven by the meteorological fields from }\end{array}$ \\
& AM3-base with $\mathrm{L}+\mathrm{W}=1.5 \mathrm{~cm}^{3} \mathrm{~m}^{-3}$ \\
\hline
\end{tabular}

Dynamics Laboratory (GFDL) (Donner et al., 2011). The default set-up for AM3 with prescribed climatological sea surface temperature/ice and latest physics was also used. Both CAM5 and AM3 models have their own active aerosol modules in which aerosols can interact with radiation, cloud microphysics and affect the meteorology. Outputs from the two models used to drive the offline IMPACT model included temperature, pressure, wind speeds, humidity, specific humidity change due to moist processes, cloud fraction, cloud water, precipitation, convective mass flux, detrainment rate, boundary layer height, and vertical diffusivity coefficient. We also compare the predicted aerosol fields from IMPACT to those simulated natively with CAM5 and AM3. Since the predicted aerosols from IMPACT are somewhat different than those from the active aerosol modules in each model, there is a small inconsistency between the predicted aerosols and the meteorology from each model. However, we believe the difference in the meteorology between the CAM5 and AM3 models plays the dominant role on the differences in predicted aerosol fields. The meteorological fields from both models that were used to drive IMPACT have a time resolution of $3 \mathrm{~h}$. The CAM5 data have 30 vertical layers from the surface to $2.25 \mathrm{hPa}$ with a horizontal resolution of $1.9^{\circ} \times 2.5^{\circ}$. The original AM3 data were interpolated from a cubic sphere to a regular lat-lon grid for use by IMPACT. The interpolated data have a horizontal resolution of $2^{\circ} \times 2.5^{\circ}$ and 48 layers. In our simulations, the first top 11 layers are discarded and the next 14 layers are collapsed into 7 layers. Therefore, the AM3 data used here also have 30 layers and a top that is very close to $2.25 \mathrm{hPa}$. The IMPACT model has a versatile grid resolution and simply uses the same basic grid from each set of meteorological fields.

\subsection{Set-up of simulations}

Table 2 shows the simulations performed for this study. CAM5-base and AM3-base are the default set-up of the stand-alone CAM5 and AM3 models. C1 is the IMPACT model driven by the meteorological fields from CAM5 with $\mathrm{L}+\mathrm{W}$, the condensed water content in precipitating cloud, equal to $0.5 \mathrm{~cm}^{3} \mathrm{~m}^{-3} ; \mathrm{C} 2$ is the IMPACT model driven CAM5 with $\mathrm{L}+\mathrm{W}$ equal to $1.5 \mathrm{~cm}^{3} \mathrm{~m}^{-3}$; $\mathrm{A} 1$ is the $\mathrm{IM}-$ PACT model driven by the meteorological fields from AM3 with $\mathrm{L}+\mathrm{W}$ equal to $0.5 \mathrm{~cm}^{3} \mathrm{~m}^{-3}$; $\mathrm{A} 2$ is the IMPACT model driven by the meteorological fields from AM3 with $\mathrm{L}+\mathrm{W}$ equal to $1.5 \mathrm{~cm}^{3} \mathrm{~m}^{-3}$.

2-yr consecutive meteorological fields from CAM5-base and AM3-base were used in C1/C2 and A1/A2, respectively. Both PD and PI emissions were used in all four cases. Only the results from the simulations with PD emissions were used to analyze the differences in the predicted aerosol fields from CAM5 and AM3 (see Sects. 4.1 to 4.2). Results from the simulations with both PD and PI emissions were used to calculate the anthropogenic radiative forcing in Sect. 4.3.

\section{Meteorological fields comparison}

Wind fields play an important role in determining the advection of gases and aerosols from the polluted continents to remote areas. Figure 1 compares the horizontal winds from the two meteorological data sets near the surface and at $\sim 550 \mathrm{hPa}$ in January and July from the second year meteorological fields (also see Fig. S1 in the Supplement for the wind field differences). The overall features of the two data sets are quite similar. However, some obvious differences can be observed. In January, CAM5 has stronger stationary wave activity at high latitudes in the Northern Hemisphere (NH). Larger wind speeds can be seen blowing from north Asia to the North Pole near both the surface and around $550 \mathrm{hPa}$. In both months, AM3 has stronger winds blowing from Africa to South America around the Equator at $\sim 550 \mathrm{hPa}$. We note that the comparisons outlined here were also true for five year simulations, so are not due to interannual variability.

The vertical transport of aerosols in IMPACT is implemented through three different processes: resolved largescale convergence, subgrid scale convection, and vertical diffusion. The first process, large-scale convergence, is calculated implicitly together with the advection, while the other two processes are calculated explicitly. Figure 2 shows the annual zonal mean updraft convective cloud mass fluxes and vertical diffusivity coefficients for heat and moisture from CAM5 and AM3, which determine these two processes. The updraft cloud mass fluxes include the cloud mass fluxes from both the deep and shallow convection. Overall, the cloud mass flux from CAM5 is larger than that from AM3 everywhere by a factor of $\sim 2$ except in the region around $200 \mathrm{hPa}$ near the equatorial tropopause. The vertical diffusion which employs different diagnostic schemes in CAM5 (Bretherton and Park, 2009) and AM3 (Anderson et al., 2004) has quite different coefficients: CAM5 has a larger diffusivity coefficient than AM3 in the tropical and mid-latitude regions below $700 \mathrm{hPa}$ by a factor of $\sim 2$; above $700 \mathrm{hPa}$, AM3 has a larger vertical diffusivity coefficient over mid-latitudes but the values in this region are very small. With its larger cloud 

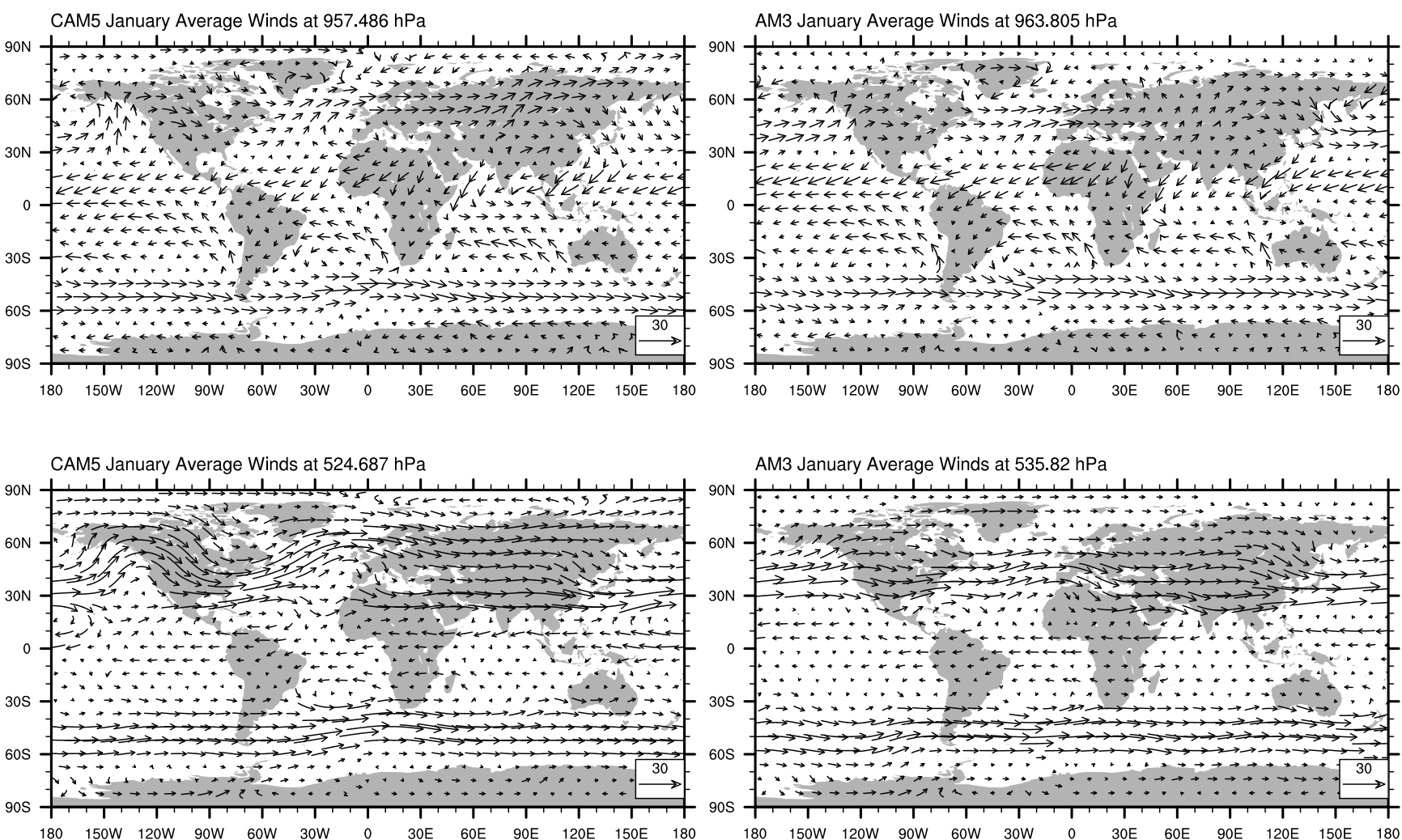

AM3 January Average Winds at $535.82 \mathrm{hPa}$

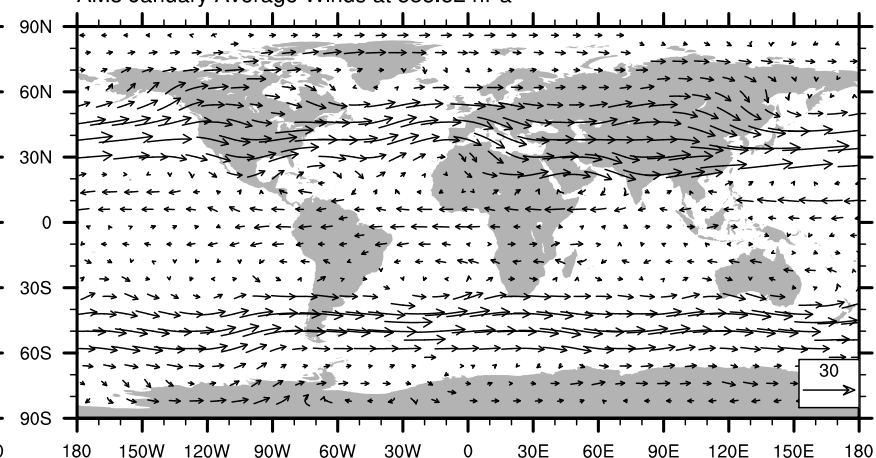

CAM5 July Average Winds at $957.486 \mathrm{hPa}$

AM3 July Average Winds at $963.805 \mathrm{hPa}$
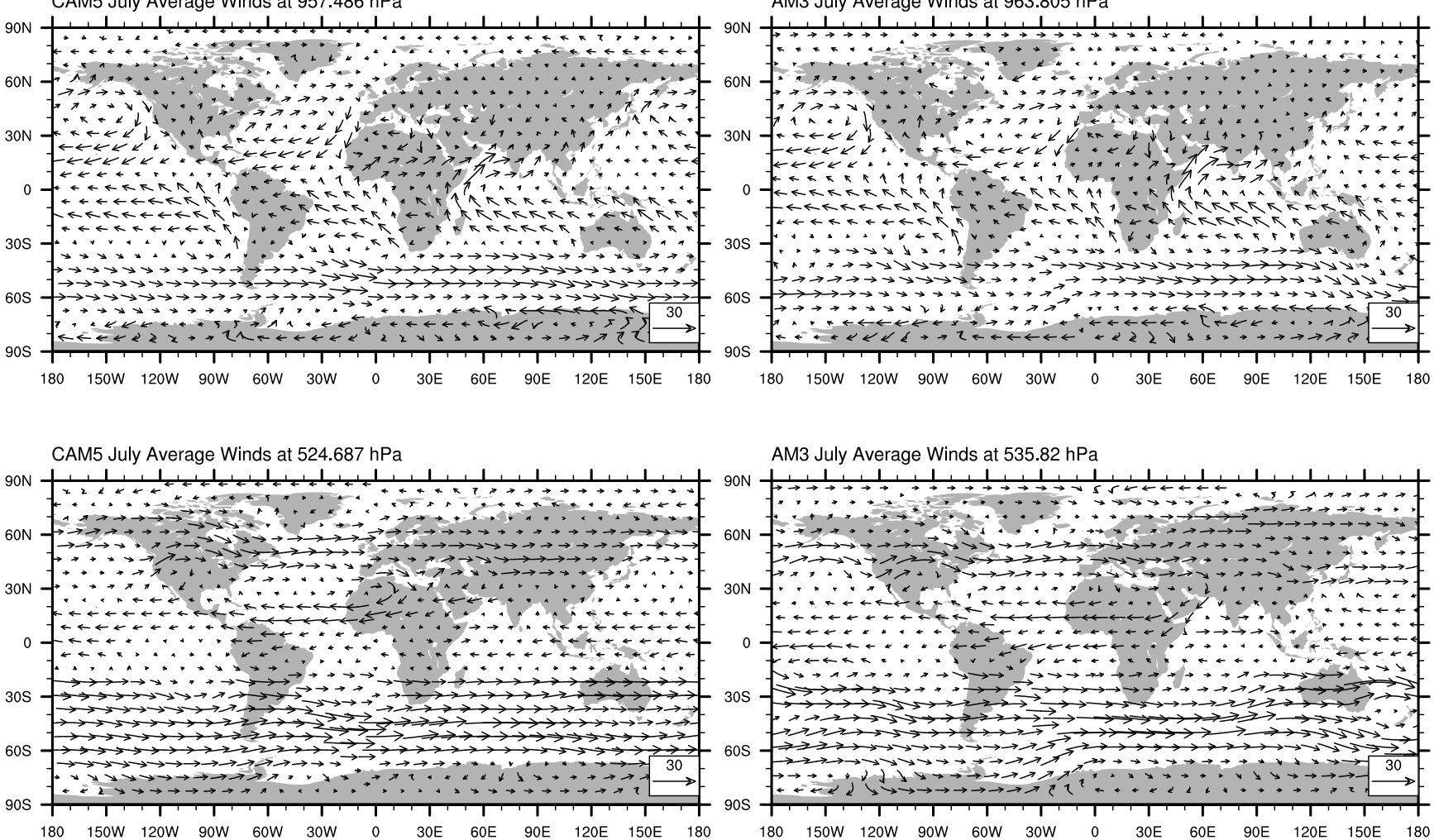

Fig. 1. Vectors of horizontal winds near $950 \mathrm{hPa}$ and $550 \mathrm{hPa}$ in January and July from CAM5 (left) and AM3 (right). The maximum magnitude drawn is $30 \mathrm{~m} \mathrm{~s}^{-1}$ 

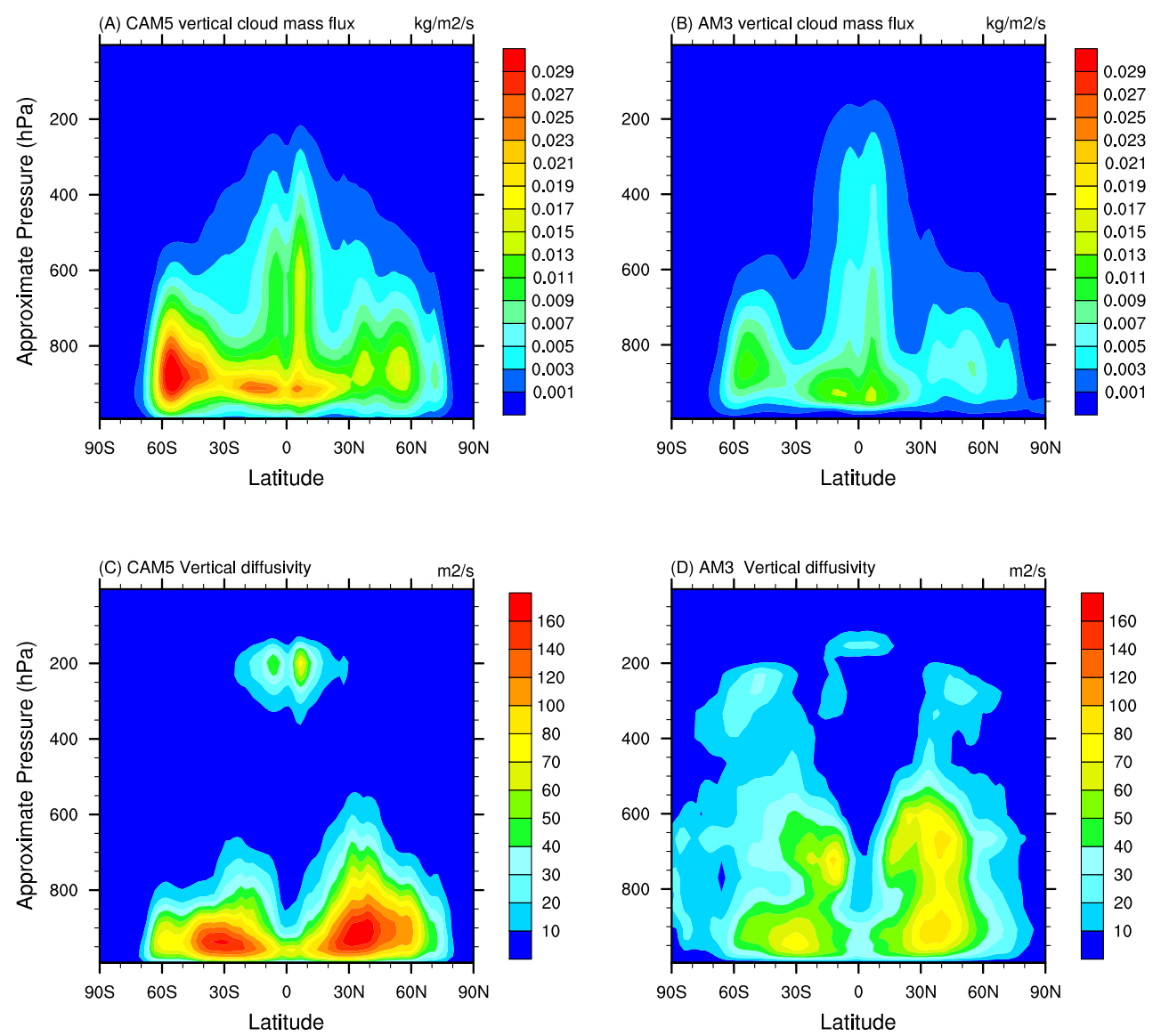

Fig. 2. Annual zonal mean convective cloud mass flux (top) and vertical diffusivity coefficient (bottom) from CAM5 (left) and AM3 (right).

mass flux and larger diffusivity coefficient at the lower levels, one can expect that the meteorological fields from CAM5 are more efficient at lifting aerosol up from the surface. However, since the wet deposition of aerosols in convective updrafts is tightly related to the amount of cloud mass flux, a stronger cloud mass flux also leads to more wet scavenging and may not necessarily lead to higher aerosol concentrations aloft.

The large-scale precipitation fields, which also play an important role in the wet scavenging, are shown in Fig. 3. Figure $3 \mathrm{a}$ and $3 \mathrm{~b}$ show the global distribution of large-scale precipitation and Fig. $3 c$ compares the zonal means. The annual average global mean value from AM3, $1.11 \mathrm{~mm}_{\text {day }}{ }^{-1}$, is $28 \%$ larger than the value of $0.87 \mathrm{~mm} \mathrm{day}^{-1}$ from CAM5 (significantly different at the $99 \%$ confidence level). Most of the differences occur in regions between $60 \mathrm{~S}$ and $60 \mathrm{~N}$. Regionally, AM3 has more large-scale precipitation over North America, extratropical subsiding areas, mid-latitudes in the Southern Hemisphere $(\mathrm{SH})$ and the storm track region in the North Pacific Ocean. However, AM3 has less large-scale precipitation in Brazil and the area from central to northern Africa.

The in-cloud liquid water content and cloud fraction play a key role in the chemical production of sulfate aerosol.
The top and middle graphs of Fig. 4 compare the annually and zonally averaged in-cloud liquid water content and total cloud fraction. These determine the aqueous phase reaction between $\mathrm{SO}_{2}$ and $\mathrm{H}_{2} \mathrm{O}_{2} / \mathrm{O}_{3}$ as well as the ratio of the production rate in the aqueous-phase to the production rate in the gas-phase. An obvious difference in this figure is that AM3 has much larger in-cloud liquid water content over equatorial regions in middle to upper troposphere by a factor of $\sim 3$. However, since the AM3 total cloud fraction is smaller in this region, the grid box averaged liquid water content is actually very similar for both models in the tropics (figures are not shown). Over mid-latitudes, AM3 has higher in-cloud liquid water content as well as grid box averaged liquid water content. Therefore, AM3 favors a higher ratio of the oxidation rate of $\mathrm{SO}_{2}$ in the aqueous-phase to that in the gas-phase, as shown in Table 4. (Details will be explained in next section.) The bottom graphs of Fig. 4 compare the annually and zonally averaged relative humidity from the two GCMs. Relative humidity plays an important role in water uptake by aerosols and thus has important impact on the aerosol optical depth and aerosol direct effect. CAM5 has a higher relative humidity especially at high latitudes. Figure 5 compares the annual mean total grid box averaged liquid water path (LWP) as well 

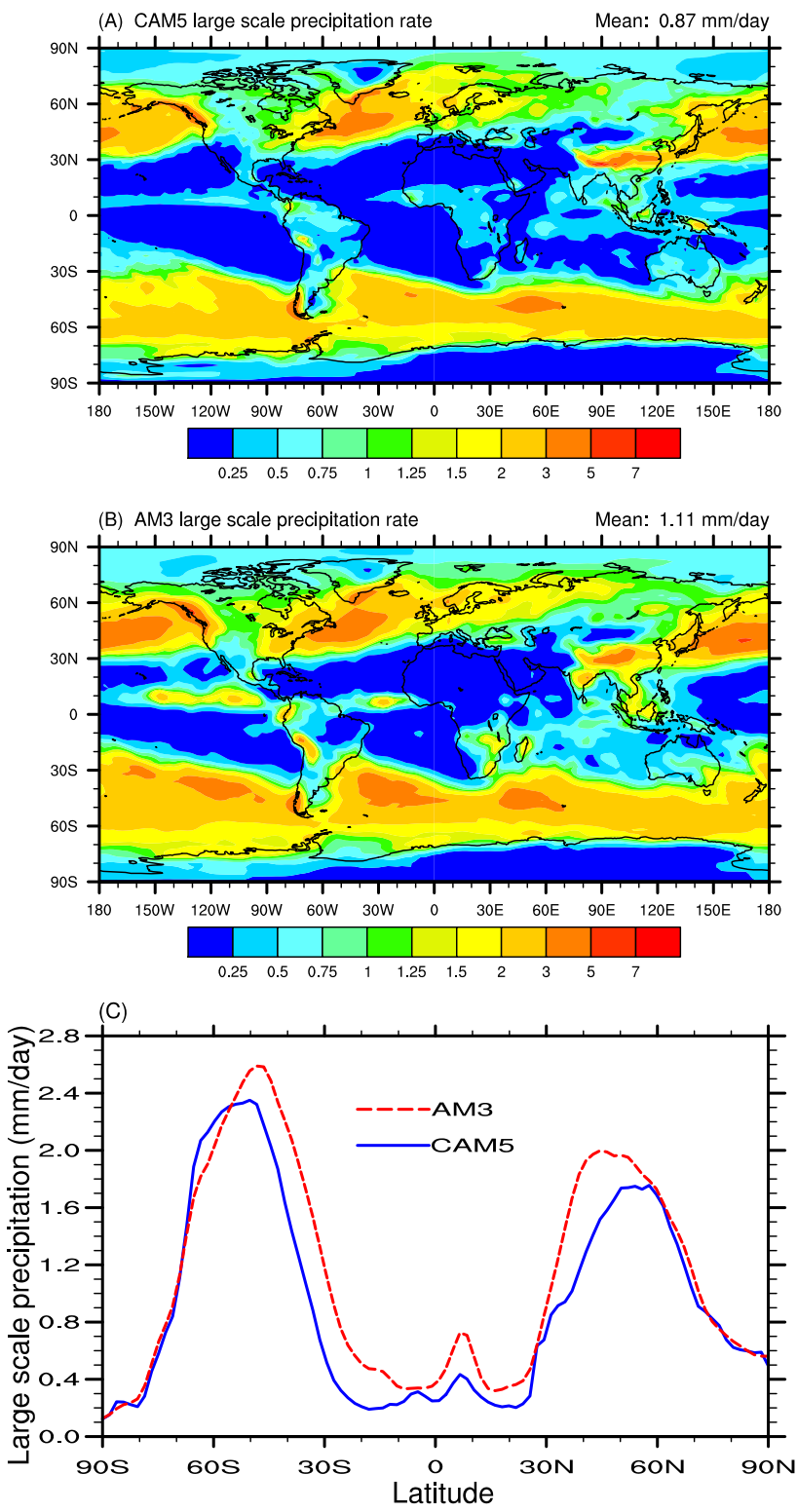

Fig. 3. Annual average surface total large-scale precipitation $\left(\mathrm{mm} \mathrm{day}^{-1}\right.$ ) from CAM5 and AM3. (A) CAM5, (B) AM3, and (C) the annual zonal average surface large-scale precipitation $\left(\mathrm{mm}\right.$ day $\left.^{-1}\right)$.

as the LWP of large-scale clouds. AM3 has a slightly larger total LWP than CAM5 (51 $\mathrm{g} \mathrm{m}^{-2}$ versus $\left.47.7 \mathrm{~g} \mathrm{~m}^{-2}\right)$, but a much larger LWP of large-scale clouds $\left(40.6 \mathrm{~g} \mathrm{~m}^{-2}\right.$ versus $29.8 \mathrm{~g} \mathrm{~m}^{-2}$ ). The sulfate produced in large-scale clouds contributes more to the burden and longer lifetime of sulfate than the sulfate produced in convective clouds because the sulfate produced in convective clouds is removed more quickly due to the shorter lifetime of convective clouds as well as their larger tendency to produce precipitation.

\section{Model results for aerosols}

In the following sections, we analyze the results from the second year of the simulations. The aerosol burdens and lifetimes from the six cases listed in Table 2 with present day emissions are summarized in Table 3. For the two base-line models, CAM5 has smaller burdens and shorter lifetimes of sulfate, OM, BC and dust, while the sea-salt burden is larger. Since these two base-line models not only have different meteorological fields but also different aerosol microphysics modules, identifying the reasons causing such differences is beyond the scope of present paper. Nevertheless, Table 3 shows that except for dust and sea salt, the tendency of the differences predicted in the off-line IMPACT model is similar to that between the base-line models. Thus, we might suspect that many of the differences reported between these two base-line models are associated with meteorology, rather than aerosol treatments.

The burdens and lifetimes of aerosols from case $\mathrm{C} 1$ are smaller than those from case A1. This is also true between $\mathrm{C} 2$ and A2. Since the sole reason for such differences between $\mathrm{C} 1$ and $\mathrm{A} 1$ (or between $\mathrm{C} 2$ and $\mathrm{A} 2$ ) is that we used different meteorological fields, we can use these results to analyze which meteorological processes cause these differences. The major factor causing these differences is that CAM5 has much larger convective cloud mass flux than AM3 as shown in Fig. 2. The stronger mass flux leads to stronger in-cloud wet scavenging of aerosols in convective updrafts (as explained in detail below).

When we increase the condensed water content $(\mathrm{L}+\mathrm{W})$ in precipitating stratus clouds from $0.5 \mathrm{~cm}^{3} \mathrm{~m}^{-3}$ to $1.5 \mathrm{~cm}^{3} \mathrm{~m}^{-3}$ from case $\mathrm{C} 1$ to $\mathrm{C} 2$ or $\mathrm{A} 1$ to $\mathrm{A} 2$, the burdens and lifetimes increase. When $\mathrm{L}+\mathrm{W}$ increases, the fraction of each grid box experiencing precipitation decreases thereby decreasing the in-cloud rainout and below-cloud washout by large-scale precipitation (see Sect. 2.1). The changes from $\mathrm{A} 1$ to $\mathrm{A} 2$ are larger than the changes from $\mathrm{C} 1$ to $\mathrm{C} 2$. For example, the burden of sulfate increases by $34 \%$ from A1 to A 2 but only by $24 \%$ from $\mathrm{C} 1$ to $\mathrm{C} 2$. This is because AM3 has more large-scale precipitation than CAM5 on a global scale. Therefore, the results using the AM3 meteorological fields are more sensitive to the change of $\mathrm{L}+\mathrm{W}$.

\subsection{Global aerosol budgets}

The global budgets of the simulated aerosols and their precursors are shown in Tables 4-7. We also list the mean and stand deviation from the Aerosol Model Intercomparison Initiative intercomparison study (AeroCom, see Textor et al., 2006, Table 10).

Table 4 shows the budget for sulfate. The total sources of sulfate vary from $63.02 \mathrm{Tg} \mathrm{yr}^{-1}$ to $67.38 \mathrm{Tg} \mathrm{yr}^{-1}$, which are larger than the mean value $\left(59.67 \mathrm{Tg} \mathrm{yr}^{-1}\right)$ from AeroCom. $\mathrm{A} 1$ and $\mathrm{A} 2$ predict a higher production rate of sulfate from the aqueous-phase than does C1 and C2. A1 (A2) predicts 

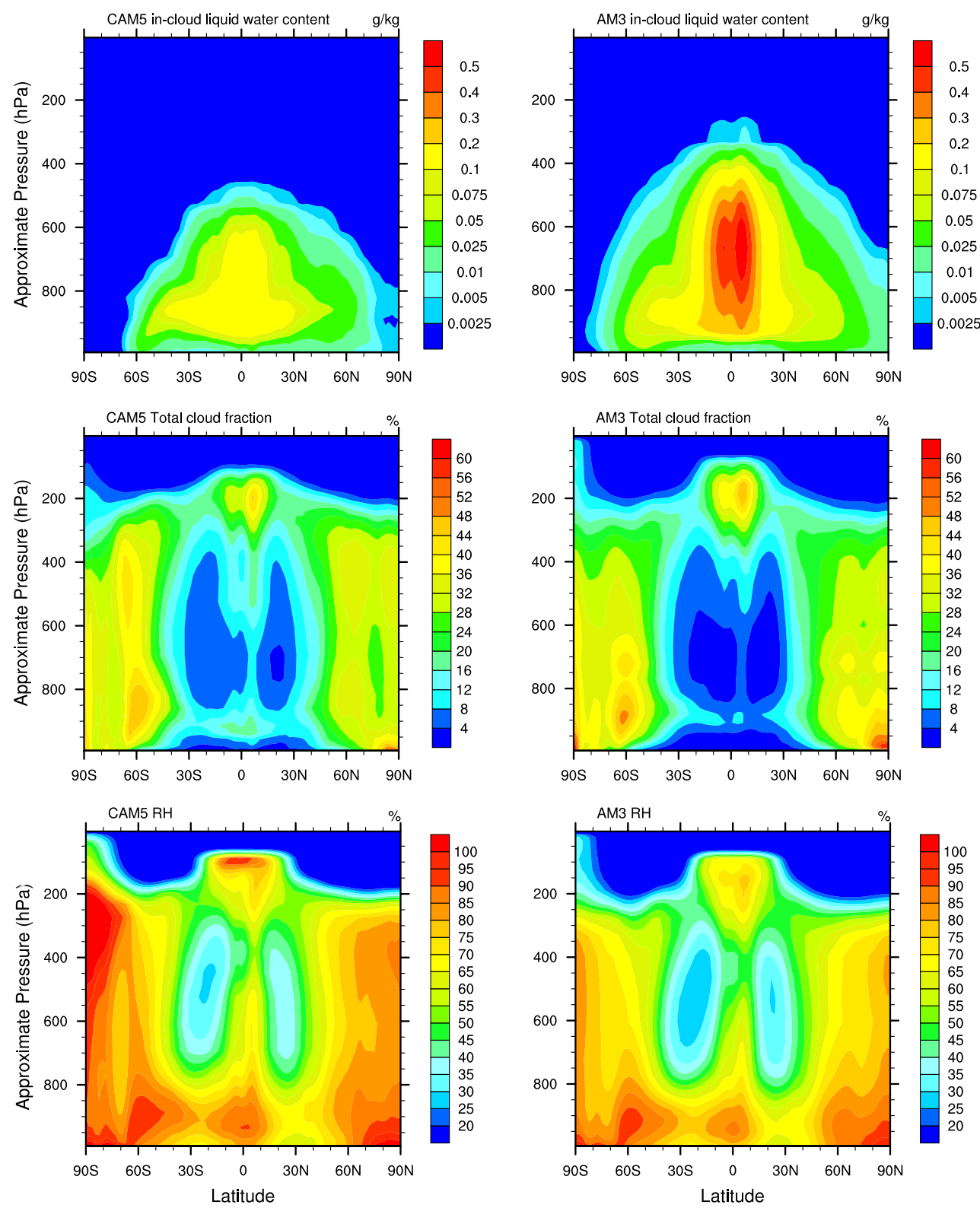

Fig. 4. Annual zonal mean in-cloud liquid water content (top), total cloud fraction (middle) and relative humidity(bottom) from CAM5 (left) and AM3 (right).

that $67.0 \%(67.9 \%)$ of the total sulfate is produced in the aqueous-phase while $\mathrm{C} 1(\mathrm{C} 2)$ only predicts $60.5 \%$ (61.2\%). This is expected since AM3 has larger in-cloud liquid water content, which favors aqueous-phase oxidation. Consequently, the contribution of the gas-phase oxidation of $\mathrm{SO}_{2}$ to the sulfate source is smaller in A1 than $\mathrm{C} 1$ (31.2\% versus $37.6 \%$ ). This partly explains why A1 predicts a smaller fraction of sulfate in the nucleation/Aitken modes than $\mathrm{C} 1$ $(4.7 \%$ versus $6.8 \%)$ since the major source of sulfate for these two modes is the nucleation and condensation of gasphase $\mathrm{H}_{2} \mathrm{SO}_{4}$ which is only produced from gas-phase oxidation of $\mathrm{SO}_{2}$. $\mathrm{C} 1$ predicts that $83.5 \%$ of the total sulfate mass is in the form of pure sulfate $(0.03 \%$ in the nucleation mode, $6.8 \%$ in the Aitken mode and $76.7 \%$ in the accumulation mode) with the remaining $16.5 \%$ coated on nonsulfate aerosols $(11.7 \%$ on $\mathrm{OM}$ and $\mathrm{BC}, 4.0 \%$ on dust and $0.8 \%$ on sea salt). A1 predicts a lower percentage, $80.5 \%$, of the total sulfate mass is in the form of pure sulfate $(0.03 \%$ in the nucleation mode, $4.6 \%$ in the Aitken mode and $75.8 \%$ in the accumulation mode) but a higher percentage, $19.5 \%$, coated on nonsulfate aerosols (13.6\% on OM and BC, $4.5 \%$ on dust and $1.4 \%$ on sea salt). When we reduce the amount of wet scavenging of aerosols by the large-scale precipitation, the mass fraction of sulfate on nonsulfate aerosols increases 

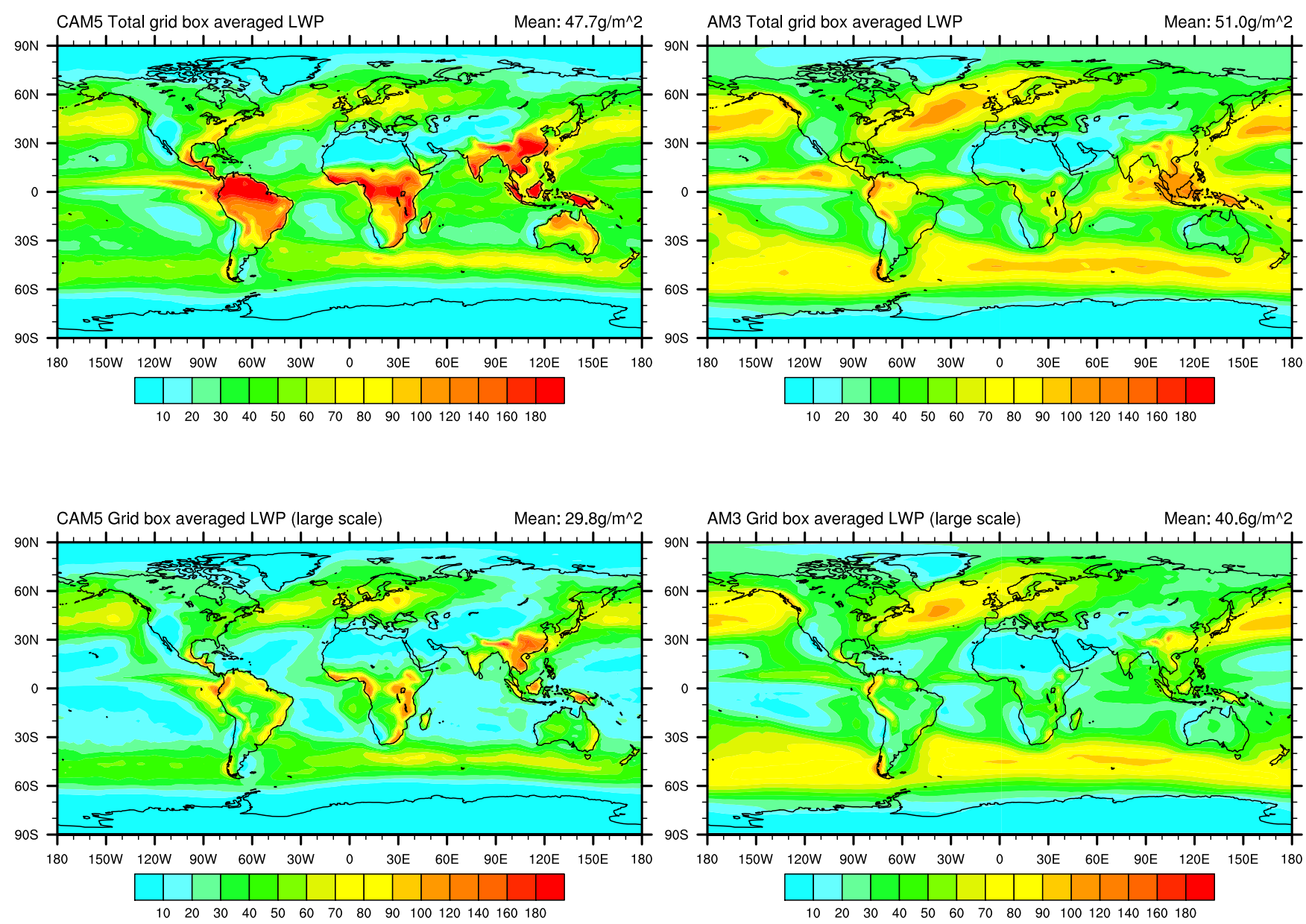

Fig. 5. Annual average total grid box averaged liquid water path (LWP) (top) and the large scale LWP (bottom) from CAM5 (left) and AM3 (right).

Table 3. Summary of Global Burdens (Tg) (in bold) and Lifetimes (days) (in italic).

\begin{tabular}{lllllllllllll}
\hline Case & \multicolumn{2}{c}{ CAM5-base } & \multicolumn{2}{c}{ AM3-base } & \multicolumn{2}{c}{ C1 } & \multicolumn{2}{c}{ C2 } & \multicolumn{2}{c}{ A1 } \\
\hline & Burden & Lifetime & Burden & Lifetime & Burden & Lifetime & Burden & Lifetime & Burden & Lifetime & Burden & Lifetime \\
\hline $\mathrm{SO}_{4}^{*}$ & $\mathbf{0 . 5 3}$ & 4.50 & $\mathbf{0 . 7 9}$ & 8.08 & $\mathbf{0 . 7 1}$ & 4.08 & $\mathbf{0 . 8 8}$ & 4.98 & $\mathbf{0 . 8 8}$ & 4.85 & $\mathbf{1 . 1 8}$ & 6.33 \\
\hline $\mathrm{OM}$ & $\mathbf{0 . 7 5}$ & 5.47 & $\mathbf{1 . 7 8}$ & 7.06 & $\mathbf{0 . 8 2}$ & 3.84 & $\mathbf{0 . 9 9}$ & 4.67 & $\mathbf{1 . 0 4}$ & 4.90 & $\mathbf{1 . 3 5}$ & 6.37 \\
\hline $\mathrm{BC}$ & $\mathbf{0 . 1 0}$ & 4.92 & $\mathbf{0 . 1 3}$ & 6.59 & $\mathbf{0 . 1 1}$ & 3.64 & $\mathbf{0 . 1 3}$ & 4.56 & $\mathbf{0 . 1 3}$ & 4.36 & $\mathbf{0 . 1 7}$ & 5.89 \\
\hline Dust & $\mathbf{2 4 . 7 2}$ & 2.76 & $\mathbf{1 4 . 9 8}$ & 4.95 & $\mathbf{2 2 . 3 7}$ & 3.47 & $\mathbf{2 4 . 9 8}$ & 3.87 & $\mathbf{2 6 . 0 9}$ & 4.04 & $\mathbf{3 0 . 0 4}$ & 4.66 \\
\hline Sea salt & $\mathbf{1 1 . 3 5}$ & 0.87 & $\mathbf{6 . 3 7}$ & 0.42 & $\mathbf{4 . 6 9}$ & 0.35 & $\mathbf{6 . 2 7}$ & 0.47 & $\mathbf{5 . 8 8}$ & 0.45 & $\mathbf{8 . 9 4}$ & 0.68 \\
\hline
\end{tabular}

* The unit for $\mathrm{SO}_{4}$ is $\mathrm{Tg} \mathrm{S}$.

from $16.5 \%$ to $19.5 \%$ for case $\mathrm{C} 1$ to $\mathrm{C} 2$ and from $19.5 \%$ to $23.7 \%$ for case A1 to A2. Since the sulfate produced by the aqueous phase oxidation in clouds is equally distributed among all particles that have acted as CCN (details are described in Liu et al. (2005)), the increased preexisting surfaces of nonsulfate aerosols in the aqueous-phase reactions increase the amount of sulfate coated on them. The aerosol burdens from all four cases are larger than the AeroCom mean value due to both the larger sources as well as smaller removal rates. The wet scavenging of sulfate in wet convective updrafts accounts for $47.7 \%$ of the total wet deposition in $\mathrm{C} 1$ and increases to $61.6 \%$ in $\mathrm{C} 2$ while $\mathrm{A} 1$ and $\mathrm{A} 2$ have much smaller values $(25.1 \%$ and $37.5 \%)$. The larger values are due to the larger vertical convective cloud mass flux and 
Table 4. Global budget of sulfate aerosol.

\begin{tabular}{|c|c|c|c|c|c|c|}
\hline \multirow[b]{2}{*}{ Case } & \multirow[b]{2}{*}{$\mathrm{C} 1$} & \multirow[b]{2}{*}{$\mathrm{C} 2$} & \multirow[b]{2}{*}{$\mathrm{A} 1$} & \multirow[b]{2}{*}{$\mathrm{A} 2$} & \multicolumn{2}{|c|}{ AeroCom $^{\mathrm{a}}$} \\
\hline & & & & & Mean & Stdev \\
\hline Sources $\left(\mathrm{Tg} \mathrm{yr}^{-1}\right)$ & 63.02 & 63.99 & 65.69 & 67.38 & 59.67 & 22 \\
\hline Emission & 1.23 & 1.23 & 1.23 & 1.23 & & \\
\hline Gas-phase $\mathrm{SO}_{2}$ oxidation & 23.68 & 23.60 & 20.48 & 20.42 & & \\
\hline Aqueous-phase $\mathrm{SO}_{2}$ oxidation & 38.11 & 39.17 & 43.98 & 45.73 & & \\
\hline Removal rate coeff $\left(\right.$ day $\left.^{-1}\right)$ & 0.25 & 0.20 & 0.21 & 0.16 & 0.25 & 18 \\
\hline Dry deposition & 0.02 & 0.02 & 0.01 & 0.01 & 0.03 & 55 \\
\hline Wet deposition & 0.23 & 0.19 & 0.20 & 0.15 & 0.22 & 22 \\
\hline In convective updrafts $(\%)$ & 47.7 & 61.6 & 25.1 & 37.5 & & \\
\hline By large scale precip (\%) & 52.3 & 38.4 & 74.9 & 62.5 & & \\
\hline Wet/Total (\%) & 93.8 & 92.4 & 94.5 & 92.2 & 88.50 & 8 \\
\hline Burden $(\operatorname{Tg} S)$ & 0.71 & 0.88 & 0.88 & 1.18 & 0.66 & 25 \\
\hline Gas-phase $\mathrm{H}_{2} \mathrm{SO}_{4}(\%)$ & 0.05 & 0.03 & 0.04 & 0.02 & & \\
\hline Pure sulfate - Nucleation (\%) & 0.03 & 0.02 & 0.03 & 0.02 & & \\
\hline Pure sulfate - Aitken $(\%)$ & 6.78 & 4.90 & 4.64 & 3.37 & & \\
\hline Pure sulfate - Accumulation (\%) & 76.68 & 75.56 & 75.82 & 72.88 & & \\
\hline On carbonaceous aerosols (\%) & 11.73 & 14.11 & 13.58 & 16.75 & & \\
\hline On dust $(\%)$ & 3.93 & 4.11 & 4.54 & 4.59 & & \\
\hline On sea salt $(\%)$ & 0.79 & 1.26 & 1.35 & 2.37 & & \\
\hline In polar regions ${ }^{\mathrm{b}}(\%)$ & 0.80 & 1.05 & 0.82 & 1.04 & 5.91 & 55 \\
\hline Above $5 \mathrm{~km}(\%)$ & 43.01 & 40.76 & 45.57 & 41.44 & 32.23 & 36 \\
\hline Lifetime (days) & 4.07 & 4.98 & 4.85 & 6.33 & 4.12 & 18 \\
\hline
\end{tabular}

\footnotetext{
a Mean values and standard deviations(\%) are from available models in AeroCom [see Textor et al. 2006, Table 10]. The standard deviations have been normalized by the all models average in the percentage in AeroCom.

b South of $80^{\circ} \mathrm{S}$ and north of $80^{\circ} \mathrm{N}$.
}

smaller large-scale precipitation from CAM5. The mass fraction of sulfate in the polar regions (poleward of $80^{\circ}$ latitude) are similar between $\mathrm{C} 1$ and $\mathrm{A} 1(0.80 \%$ versus $0.82 \%)$ or $\mathrm{C} 2$ and A2 (1.05\% versus $1.04 \%)$, but are much smaller than the mean value reported for AeroCom, 5.91\%. This is also true for other aerosols (see below). As pointed out by Wang et al. (2009), this may be due to the differences in the wet removal mechanism and the efficiency of transport to the poles between our model and other models in AeroCom. The mass fraction of sulfate above $5 \mathrm{~km}$ is larger than that from AeroCom (43.0\% for $\mathrm{C} 1,40.8 \%$ for $\mathrm{C} 2,45.6 \%$ for $\mathrm{A} 1,41.4 \%$ for A2 versus $32.2 \%$ for AeroCom).

Table 5 compares the global budget for $\mathrm{OM}$ and $\mathrm{BC}$. The burdens and lifetimes of both $\mathrm{OM}$ and $\mathrm{BC}$ in the four simulations are smaller than those from AeroCom due to the smaller emissions as well as the larger removal rates. As explained in Liu et al. (2005), most carbonaceous aerosols are internally mixed with sulfate and are generally hygroscopic except freshly emitted soot particles, which makes the wet removal rate larger than that in many other models. The burden of OM from $\mathrm{C} 1 / \mathrm{C} 2$ is smaller than that from A1/A2 (0.82 Tg versus $1.04 \mathrm{Tg}$ and $0.99 \mathrm{Tg}$ versus $1.35 \mathrm{Tg}$ ) due to its larger wet removal rate, which is mainly caused by the larger wet scavenging in convective updrafts in $\mathrm{C} 1$ and $\mathrm{C} 2$. However, $\mathrm{C} 1$ has a larger mass fraction above $5 \mathrm{~km}$ than does A1 $(13.6 \%$ versus $11.6 \%$ ). This is likely due to the stronger cloud mass flux from CAM5, which is therefore more effective at transporting aerosols vertically. A larger vertical diffusivity coefficient below $700 \mathrm{hPa}$ in CAM5 may also contribute to the larger fraction above $5 \mathrm{~km}$. $\mathrm{C} 1$ also has a larger mass fraction in polar regions than does A1 $(0.18 \%$ versus $0.12 \%)$. There are several possible factors that may cause this difference. First, because of the stronger cloud mass flux from CAM5, more OM is lifted to upper levels where it is subject to less rainout/washout by large-scale precipitation and thus is able to be transported longer distances from its source. Second, CAM5 has less large-scale precipitation and thus less rainout and washout. Third, AM3 has a higher aqueous-phase $\mathrm{SO}_{2}$ oxidation rate which leads to more sulfate coating on nonsulfate aerosols. In internally mixed $\mathrm{OM}$ and sulfate, the global average ratio of $\mathrm{S}$ to $\mathrm{OM}$ is $8.6 \%$ for $\mathrm{C} 1$ and $9.8 \%$ for A1. This ratio is even higher for A1 in mid-latitudes in the NH where A1 has more sulfate than $\mathrm{C} 1$ but similar amounts of OM (see Fig. 6). When there is more sulfate coated on $\mathrm{OM}$ as in $\mathrm{A} 1, \mathrm{OM}$ is more hydroscopic and has a larger wet scavenging efficiency.

When we reduce the wet deposition by large-scale precipitation, the total burden of $\mathrm{OM}$ increases from $0.82 \mathrm{Tg}$ in $\mathrm{C} 1$ to $0.99 \mathrm{Tg}$ in $\mathrm{C} 2$ and the mass fraction in polar regions is doubled from $0.18 \%$ to $0.36 \%$. The change in going from A1 to A2 is even larger: the total burden increases from $1.04 \mathrm{Tg}$ to $1.35 \mathrm{Tg}$ and the mass fraction in polar 
Table 5. Global budget of OM and BC.

\begin{tabular}{|c|c|c|c|c|c|c|}
\hline \multirow[b]{2}{*}{ Case } & \multirow[b]{2}{*}{$\mathrm{C} 1$} & \multirow[b]{2}{*}{$\mathrm{C} 2$} & \multirow[b]{2}{*}{ A1 } & \multirow[b]{2}{*}{$\mathrm{A} 2$} & \multicolumn{2}{|c|}{ AeroCom $^{\mathrm{a}}$} \\
\hline & & & & & Mean & Stdev \\
\hline \multicolumn{7}{|c|}{$\mathrm{OM}$} \\
\hline Sources $\left(\mathrm{Tg} \mathrm{yr}^{-1}\right)$ & 77.62 & 77.62 & 77.62 & 77.62 & 96.60 & 26 \\
\hline Fossil fuel emission & 15.78 & 15.78 & 15.78 & 15.78 & & \\
\hline Biomass burning emission & 47.39 & 47.39 & 47.39 & 47.39 & & \\
\hline Photochemistry from terpenes & 14.46 & 14.46 & 14.46 & 14.46 & & \\
\hline Removal rate coeff $\left(\right.$ day $\left.^{-1}\right)$ & 0.26 & 0.21 & 0.20 & 0.16 & 0.16 & 4 \\
\hline Dry deposition & 0.03 & 0.03 & 0.02 & 0.02 & 0.03 & 49 \\
\hline Wet deposition & 0.23 & 0.19 & 0.18 & 0.13 & 0.14 & 32 \\
\hline In convective updraft $(\%)$ & 64.6 & 78.9 & 42.4 & 56.7 & & \\
\hline By large scale precip (\%) & 35.4 & 21.1 & 57.6 & 43.3 & & \\
\hline Wet/Total $(\%)$ & 89.5 & 88.3 & 87.8 & 85.6 & 79.9 & 16 \\
\hline Burden $(\mathrm{Tg})$ & 0.82 & 0.99 & 1.04 & 1.35 & 1.70 & 27 \\
\hline In polar ${ }^{\mathrm{b}}(\%)$ & 0.18 & 0.36 & 0.12 & 0.28 & 3.27 & 76 \\
\hline Above 5 km (\%) & 13.63 & 17.22 & 11.64 & 16.19 & 20.40 & 56 \\
\hline Lifetime (days) & 3.84 & 4.67 & 4.90 & 6.37 & 6.54 & 27 \\
\hline \multicolumn{7}{|c|}{$\mathrm{BC}$} \\
\hline Sources $\left(\mathrm{Tg} \mathrm{yr}^{-1}\right)$ & 10.54 & 10.54 & 10.54 & 10.54 & 11.90 & 23 \\
\hline Fossil fuel emission & 5.83 & 5.83 & 5.83 & 5.83 & & \\
\hline Biomass burning emission & 4.71 & 4.71 & 4.71 & 4.71 & & \\
\hline Removal rate coeff $\left(\right.$ day $\left.^{-1}\right)$ & 0.27 & 0.22 & 0.23 & 0.17 & 0.15 & 21 \\
\hline Dry deposition & 0.03 & 0.03 & 0.03 & 0.03 & 0.03 & 31 \\
\hline Wet deposition & 0.24 & 0.19 & 0.20 & 0.14 & 0.12 & 55 \\
\hline In convective updraft $(\%)$ & 60.8 & 75.6 & 38.0 & 51.9 & & \\
\hline By large scale precip (\%) & 39.2 & 24.4 & 62.0 & 48.1 & & \\
\hline Wet/Total (\%) & 88.2 & 86.7 & 87.7 & 85.2 & 78.60 & 18 \\
\hline Burden $(\mathrm{Tg})$ & 0.11 & 0.13 & 0.13 & 0.17 & 0.24 & 42 \\
\hline In polarb $(\%)$ & 0.23 & 0.49 & 0.15 & 0.36 & 4.18 & 71 \\
\hline Above 5 km (\%) & 13.79 & 17.86 & 11.64 & 16.22 & 21.20 & 53 \\
\hline Lifetime (days) & 3.64 & 4.56 & 4.36 & 5.89 & 7.12 & 33 \\
\hline
\end{tabular}

a Mean values and standard deviations (\%) are from available models in AeroCom [see Textor et al. 2006,

Table 10]. The standard deviations have been normalized by the all models average in the percentage in AeroCom.

b South of $80^{\circ} \mathrm{S}$ and north of $80^{\circ} \mathrm{N}$.

regions is more than doubled from $0.12 \%$ to $0.28 \%$. This is due to the same reason as that for sulfate: the fact that there is more large-scale precipitation in AM3 makes A1 and A2 more sensitive to the change in wet deposition by large-scale precipitation. The fractions of $\mathrm{OM}$ above $5 \mathrm{~km}$ also increase from $\mathrm{C} 1 / \mathrm{A} 1$ to $\mathrm{C} 2 / \mathrm{A} 2$ (13.6\% to $17.2 \%, 11.6 \%$ to $16.2 \%)$. However, both fractions are smaller than the mean value, $21.2 \%$, from AeroCom. For all aerosols other than sulfate, which is produced above the ground, our simulations predict smaller fractions above $5 \mathrm{~km}$ than AeroCom (see below). This is likely due to the vertical transport scheme used in the IMPACT model. In order to prevent soluble tracers from being transported to the top of convective updrafts and then dispersed on the grid scale, scavenging is applied within the convective mass transport algorithm regardless of whether or not convective precipitation forms. The convective cloud mass flux includes both mass fluxes from both shallow and deep convection. However, not all shallow convection leads to convective precipitation. The comparisons of $\mathrm{BC}$ among the four simulations are very similar to those of OM (e.g., $\mathrm{BC}$ also has a smaller burden and shorter lifetime for $\mathrm{C} 1$ than A1 but a larger portion above $5 \mathrm{~km}$ and in polar regions).

Table 6 compares the budget for mineral dust. $\mathrm{C} 1$ predicts the smallest total burden $(22.37 \mathrm{Tg})$ but it is still larger than the mean value from AeroCom $(19.20 \mathrm{Tg})$ and also has a shorter lifetime, 3.47 days, compared with 4.14 days. A2 predicts the largest total burden, $30.04 \mathrm{Tg}$, and the longest lifetime, 4.66 days. The comparisons of the dust from bin 1 to bin 4 among the four simulations are quite similar to the comparisons of $\mathrm{OM} / \mathrm{BC}$ for the burden, lifetime, mass fraction above $5 \mathrm{~km}$ and in the polar regions except that the dust particles in the fourth bin, which have the largest radius and are removed mainly through sedimentation and dry deposition, are less sensitive to the change in the large-scale 
Table 6. Global budget of dust.

\begin{tabular}{|c|c|c|c|c|c|c|}
\hline \multirow[b]{2}{*}{ Case } & \multirow[b]{2}{*}{$\mathrm{C} 1$} & \multirow[b]{2}{*}{$\mathrm{C} 2$} & \multirow[b]{2}{*}{ A1 } & \multirow[b]{2}{*}{ A2 } & \multicolumn{2}{|c|}{ Aerocom $^{\mathrm{a}}$} \\
\hline & & & & & Mean & Stdev \\
\hline Emission $(0.5-10 \mu \mathrm{m})\left(\mathrm{Tg} \mathrm{yr}^{-1}\right)$ & 2356 & 2356 & 2356 & 2356 & 1840 & 49 \\
\hline Bin 1: $0.05-0.63$ & 77 & 77 & 77 & 77 & & \\
\hline Bin 2: $0.63-1.25$ & 292 & 292 & 292 & 292 & & \\
\hline Bin 3: 1.25-2.5 & 662 & 662 & 662 & 662 & & \\
\hline Bin $4: 2.5-10$ & 1325 & 1325 & 1325 & 1325 & & \\
\hline Removal rate coeff $\left(\right.$ day $\left.^{-1}\right)(0.5-10)$ & 0.29 & 0.26 & 0.25 & 0.21 & 0.31 & 62 \\
\hline Dry deposition & 0.18 & 0.16 & 0.16 & 0.14 & 0.23 & 84 \\
\hline Wet deposition & 0.11 & 0.09 & 0.09 & 0.07 & 0.08 & 42 \\
\hline In convective updraft $(\%)$ & 57.0 & 73.9 & 35.4 & 51.7 & & \\
\hline Wet/Total $(\%)$ & 38.5 & 36.8 & 37.2 & 34.5 & 33.0 & 54 \\
\hline Bin1: Removal rate coeff $\left(\right.$ day $\left.^{-1}\right)$ & 0.14 & 0.12 & 0.11 & 0.09 & & \\
\hline Dry deposition & 0.02 & 0.02 & 0.01 & 0.01 & & \\
\hline Wet deposition & 0.11 & 0.10 & 0.10 & 0.08 & & \\
\hline In convective updraft $(\%)$ & 55.9 & 73.2 & 36.2 & 52.5 & & \\
\hline Wet/Total $(\%)$ & 83.8 & 82.5 & 87.0 & 84.7 & & \\
\hline Bin2: Removal rate coeff $\left(\right.$ day $\left.^{-1}\right)$ & 0.14 & 0.12 & 0.11 & 0.10 & & \\
\hline Dry deposition & 0.02 & 0.02 & 0.02 & 0.02 & & \\
\hline Wet deposition & 0.11 & 0.10 & 0.10 & 0.08 & & \\
\hline In convective updraft $(\%)$ & 56.1 & 73.2 & 35.8 & 52.3 & & \\
\hline Wet/Total $(\%)$ & 83.1 & 81.7 & 84.3 & 81.8 & & \\
\hline Bin3: Removal rate coeff $\left(\right.$ day $\left.^{-1}\right)$ & 0.17 & 0.15 & 0.14 & 0.12 & & \\
\hline Dry deposition & 0.06 & 0.05 & 0.05 & 0.05 & & \\
\hline Wet deposition & 0.11 & 0.10 & 0.10 & 0.08 & & \\
\hline In convective updraft $(\%)$ & 56.5 & 73.5 & 35.8 & 52.2 & & \\
\hline Wet/Total $(\%)$ & 66.7 & 64.3 & 66.5 & 62.4 & & \\
\hline Bin4: Removal rate coeff $\left(\right.$ day $\left.^{-1}\right)$ & 0.86 & 0.82 & 0.80 & 0.76 & & \\
\hline Dry deposition & 0.75 & 0.74 & 0.72 & 0.71 & & \\
\hline Wet deposition & 0.10 & 0.09 & 0.07 & 0.05 & & \\
\hline In convective updraft $(\%)$ & 60.5 & 76.5 & 32.8 & 47.7 & & \\
\hline Wet/Total (\%) & 12.0 & 10.4 & 9.4 & 7.2 & & \\
\hline Burden $(\mathrm{Tg})(0.5-10 \mu \mathrm{m})$ & 22.37 & 24.98 & 26.09 & 30.04 & 19.20 & 40 \\
\hline Bin 1: 0.05-0.63 & 1.55 & 1.79 & 1.90 & 2.27 & & \\
\hline Bin 2: $0.63-1.25$ & 5.88 & 6.72 & 7.01 & 8.32 & & \\
\hline Bin 3: 1.25-2.5 & 10.70 & 12.05 & 12.62 & 14.67 & & \\
\hline Bin $4: 2.5-10$ & 4.24 & 4.42 & 4.56 & 4.78 & & \\
\hline In polar ${ }^{\mathrm{b}}(\%)(0.5-10 \mu \mathrm{m})$ & 0.11 & 0.23 & 0.07 & 0.21 & 1.54 & 102 \\
\hline Above $5 \mathrm{~km}(\%)(0.5-10 \mu \mathrm{m})$ & 9.12 & 11.21 & 7.47 & 9.70 & 14.10 & 51 \\
\hline Lifetime (days) $(0.5-10 \mu \mathrm{m})$ & 3.47 & 3.87 & 4.04 & 4.66 & 4.14 & 43 \\
\hline Bin 1: $0.05-0.63$ & 7.41 & 8.55 & 9.05 & 10.86 & & \\
\hline Bin 2: 0.63-1.25 & 7.35 & 8.41 & 8.79 & 10.44 & & \\
\hline Bin $3: 1.25-2.5$ & 5.89 & 6.64 & 6.96 & 8.09 & & \\
\hline Bin 4: $2.5-10$ & 1.17 & 1.22 & 1.26 & 1.32 & & \\
\hline
\end{tabular}

\footnotetext{
a Mean values and standard deviations (\%) are from available models in AeroCom (see Textor et al., 2006, Table 10). The standard deviations have been normalized by the all models average in the percentage in AeroCom.

b South of $80^{\circ} \mathrm{S}$ and north of $80^{\circ} \mathrm{N}$.
}

rainout/washout scheme. Readers are referred to Table 6 for the detailed numbers.

Our sea salt emission is calculated online based on the wind speed at $10 \mathrm{~m}$ above the surface and the sea surface temperature. Table 7 shows the global budget for sea salt. $\mathrm{C} 1$ and $\mathrm{C} 2$ predict a total emission of $4827 \mathrm{Tg} \mathrm{yr}^{-1}$, while $\mathrm{A} 1$ and $\mathrm{A} 2$ predict a slightly smaller value, $4797 \mathrm{Tg} \mathrm{gr}^{-1}$. The emissions of each size bin are very close between the two models. This means that CAM5 and AM3 have very similar wind speeds at $10 \mathrm{~m}$. Just like $\mathrm{OM}, \mathrm{BC}$ or dust, $\mathrm{C} 1$ predicts a smaller burden than $\mathrm{A} 1$ (4.69 Tg versus $5.88 \mathrm{Tg}$ ), a smaller lifetime ( 0.35 days versus 0.45 days), but a larger mass fraction in the polar regions $(0.22 \%$ versus $0.12 \%)$ and above $5 \mathrm{~km}(1.54 \%$ versus $1.01 \%)$ for similar reasons. 
Table 7. Global budget of sea salt.

\begin{tabular}{|c|c|c|c|c|c|c|}
\hline \multirow[b]{2}{*}{ Case } & \multirow[b]{2}{*}{$\mathrm{C} 1$} & \multirow[b]{2}{*}{$\mathrm{C} 2$} & \multirow[b]{2}{*}{ A1 } & \multirow[b]{2}{*}{$\mathrm{A} 2$} & \multicolumn{2}{|c|}{ Aerocom $^{\mathrm{a}}$} \\
\hline & & & & & Mean & Stdev \\
\hline Emission $\left(\mathrm{Tg} \mathrm{yr}^{-1}\right)(0.5-10 \mu \mathrm{m})$ & 4827 & 4827 & 4797 & 4797 & 166000 & 199 \\
\hline Bin 1: $0.05-0.63$ & 175 & 175 & 172 & 172 & & \\
\hline Bin 2: $0.63-1.25$ & 603 & 603 & 595 & 595 & & \\
\hline Bin 3: 1.25-2.5 & 1357 & 1357 & 1352 & 1352 & & \\
\hline Bin $4: 2.5-10$ & 2693 & 2693 & 2679 & 2679 & & \\
\hline Removal rate coeff $\left(\mathrm{day}^{-1}\right)(0.5-10)$ & 2.82 & 2.11 & 2.23 & 1.47 & 5.07 & 188 \\
\hline Dry deposition & 0.94 & 0.77 & 0.88 & 0.68 & 4.28 & 219 \\
\hline Wet deposition & 1.88 & 1.34 & 1.35 & 0.80 & 0.79 & 77 \\
\hline In convective updraft $(\%)$ & 67.3 & 79.9 & 39.3 & 55.7 & & \\
\hline Wet/Total $(\%)$ & 66.8 & 63.6 & 60.5 & 54.1 & 30.50 & 65 \\
\hline Bin1: Removal rate coeff $\left(\right.$ day $\left.^{-1}\right)$ & 1.60 & 1.02 & 1.35 & 0.75 & & \\
\hline Dry deposition & 0.08 & 0.06 & 0.09 & 0.07 & & \\
\hline Wet deposition & 1.52 & 0.96 & 1.26 & 0.68 & & \\
\hline In convective updraft $(\%)$ & 62.4 & 74.5 & 32.8 & 48.1 & & \\
\hline Wet/Total $(\%)$ & 94.8 & 93.8 & 93.3 & 90.9 & & \\
\hline Bin2: Removal rate coeff $\left(\right.$ day $\left.^{-1}\right)$ & 1.61 & 1.09 & 1.35 & 0.78 & & \\
\hline Dry deposition & 0.10 & 0.08 & 0.10 & 0.08 & & \\
\hline Wet deposition & 1.51 & 1.01 & 1.25 & 0.70 & & \\
\hline In convective updraft $(\%)$ & 65.0 & 76.6 & 33.6 & 49.3 & & \\
\hline Wet/Total $(\%)$ & 93.6 & 92.3 & 92.4 & 89.6 & & \\
\hline Bin3: Removal rate coeff $\left(\right.$ day $\left.^{-1}\right)$ & 2.00 & 1.43 & 1.53 & 0.95 & & \\
\hline Dry deposition & 0.29 & 0.25 & 0.27 & 0.22 & & \\
\hline Wet deposition & 1.71 & 1.18 & 1.26 & 0.72 & & \\
\hline In convective updraft $(\%)$ & 64.4 & 77.5 & 36.8 & 52.9 & & \\
\hline Wet/Total $(\%)$ & 85.6 & 82.8 & 82.3 & 76.6 & & \\
\hline Bin4: Removal rate coeff $\left(\right.$ day $\left.^{-1}\right)$ & 4.91 & 4.36 & 3.86 & 3.19 & & \\
\hline Dry deposition & 2.48 & 2.37 & 2.30 & 2.15 & & \\
\hline Wet deposition & 2.43 & 1.99 & 1.56 & 1.04 & & \\
\hline In convective updraft $(\%)$ & 71.5 & 84.2 & 45.8 & 64.5 & & \\
\hline Wet/Total $(\%)$ & 49.5 & 45.6 & 40.3 & 32.5 & & \\
\hline Burden $(\mathrm{Tg})(0.5-10 \mu \mathrm{m})$ & 4.69 & 6.27 & 5.88 & 8.94 & 7.52 & 54 \\
\hline Bin 1: 0.05-0.63 & 0.30 & 0.47 & 0.35 & 0.63 & & \\
\hline Bin 2: $0.63-1.25$ & 1.02 & 1.51 & 1.20 & 2.09 & & \\
\hline Bin $3: 1.25-2.5$ & 1.86 & 2.60 & 2.43 & 3.91 & & \\
\hline Bin $4: 2.5-10$ & 1.50 & 1.69 & 1.90 & 2.30 & & \\
\hline In polar ${ }^{\mathrm{b}}(\%)(0.5-10 \mu \mathrm{m})$ & 0.22 & 0.76 & 0.12 & 0.45 & 3.32 & 140 \\
\hline Above $5 \mathrm{~km}(\%)(0.5-10 \mu \mathrm{m})$ & 1.54 & 3.94 & 1.01 & 2.58 & 8.65 & 92 \\
\hline Lifetime (days) $(0.5-10 \mu \mathrm{m})$ & 0.35 & 0.47 & 0.45 & 0.68 & 0.48 & 58 \\
\hline Bin 1: $0.05-0.63$ & 0.62 & 0.98 & 0.74 & 1.34 & & \\
\hline Bin 2: $0.63-1.25$ & 0.62 & 0.91 & 0.74 & 1.28 & & \\
\hline Bin $3: 1.25-2.5$ & 0.50 & 0.70 & 0.66 & 1.06 & & \\
\hline Bin 4: $2.5-10$ & 0.20 & 0.23 & 0.26 & 0.31 & & \\
\hline
\end{tabular}

a Mean values and standard deviations(\%) are from available models in AeroCom (see Textor et al. 2006, Table 10). The standard deviations have been normalized by the all models average in the percentage in AeroCom.

b South of $80^{\circ} \mathrm{S}$ and north of $80^{\circ} \mathrm{N}$.

\subsection{Global and vertical distributions}

Figure 6 shows the annual mean column integrated concentration of sulfate, $\mathrm{OM}, \mathrm{BC}$, dust and sea salt from cases $\mathrm{C} 1$ and $\mathrm{A} 1$. In both cases, the dominant contributions to the burden of total sulfate come from anthropogenic sources, which are mainly located in the industrial regions in the NH espe- cially in East Asia. Since sulfate is a secondary aerosol, and its production rate is higher in $\mathrm{A} 1, \mathrm{~A} 1$ has a higher concentration than $\mathrm{C} 1$ in most regions, especially over northern Africa, Europe and to the north of $60^{\circ} \mathrm{N}$.

Although case A1 has larger total burdens of $\mathrm{OM}$ and $\mathrm{BC}$ than case $\mathrm{C} 1$ as showed in Table 5, this is not true regionally. Over the area from the central Africa towards Brazil, 
the concentrations of these aerosols from A1 are higher. This may be attributed to two factors. First, A1 has less large-scale precipitation over central Africa (see Fig. 3) where there is a major source of biomass burning. Second, A1 has stronger trade winds blowing from central Africa to South America near the Equator (see Fig. 1). However, in the mid-latitudes of the $\mathrm{NH}, \mathrm{C} 1$ has similar or even slightly higher (e.g., North America) concentrations. To the north of $60^{\circ} \mathrm{N}$, the concentration of $\mathrm{BC}$ from $\mathrm{C} 1$ is obviously higher. As explained in Sect. 4.1, this may be due several factors including more large-scale precipitation in AM3, larger convective cloud mass flux in CAM5 and more sulfate coated on OM/BC in A1. A1 predicts more dust over north Asia. However, $\mathrm{C} 1$ predicts more dust transported over the North Pacific Ocean to North America mainly due to the smaller large-scale precipitation from CAM5 in this region (see Fig. 3). A1 predicts a higher total burden of sea salt than $\mathrm{C} 1$ and this difference mainly comes from the band from $30^{\circ} \mathrm{S}-60^{\circ} \mathrm{S}$ in the $\mathrm{SH}$. In the $\mathrm{NH}, \mathrm{Cl}$ predicts that more sea salt is transported from the North Atlantic Ocean to the North Polar region. This may be related to the stronger winds in CAM5 that blow from the North Atlantic Ocean to the North Polar region in January (see Fig. 1).

Figure 7 shows the annual zonal mean concentrations of sulfate, $\mathrm{OM}, \mathrm{BC}$, dust and sea salt from case $\mathrm{C} 1$ and $\mathrm{A} 1$. A1 has more sulfate in the lower to middle troposphere over polar regions. OM, BC, dust show strong transport toward the poles in the middle troposphere, which results in higher concentrations in the middle troposphere than in the lower troposphere over these regions. $\mathrm{C} 1$ has higher concentrations of $\mathrm{OM}$ and $\mathrm{BC}$ around $300 \mathrm{hPa}$ over both polar regions than does A1. Such differences may cause a difference in ice clouds over polar regions as $\mathrm{BC}$ can act as heterogeneous ice nuclei. Over the equator around $700 \mathrm{hPa}$ to $900 \mathrm{hPa}, \mathrm{A} 1$ has higher concentration of $\mathrm{OM}$ and $\mathrm{BC}$. This is related to the higher concentration of $\mathrm{OM}$ and $\mathrm{BC}$ over central Africa as discussed above.

Figure 8 shows the annual global mean vertical profiles of sulfate, coated sulfate, $\mathrm{OM}, \mathrm{BC}$, dust and sea salt from $\mathrm{C} 1$, $\mathrm{C} 2, \mathrm{~A} 1$ and $\mathrm{A} 2$. $\mathrm{C} 1$ has smaller concentrations than $\mathrm{A} 1$ for all aerosols in the lower troposphere. However, from $500 \mathrm{hPa}$ to $200 \mathrm{hPa}, \mathrm{C} 1$ has slightly larger concentrations of OM, BC and dust; from $600 \mathrm{hPa}$ to $400 \mathrm{hPa}, \mathrm{C} 1$ has slightly larger concentration of sea salt. When we decrease the rainout and washout by large-scale precipitation, the profiles are shifted to larger values. Overall, except for sulfate, profiles from $\mathrm{C} 1$ and $\mathrm{C} 2$ decrease more slowly than profiles from $\mathrm{A} 1$ and $\mathrm{A} 2$. This is consistent with the fact that the mass fractions above $5 \mathrm{~km}$ from $\mathrm{C} 1$ and $\mathrm{C} 2$ are always larger than those from A1 and $\mathrm{A} 2$.

Figure 9 shows the annual mean vertical profiles of sulfate, coated sulfate, $\mathrm{OM}, \mathrm{BC}$, dust and sea salt averaged in the North Polar region $\left(>80^{\circ} \mathrm{N}\right)$ from $\mathrm{C} 1, \mathrm{C} 2, \mathrm{~A} 1$ and $\mathrm{A} 2$. Except for sulfate, now the profiles from $\mathrm{C} 1$ are much larger than the profiles from A1. When we decrease the rainout and washout by large-scale precipitation, the concentrations increase by a factor of $\sim 4$ from A1 to A2, a factor of $\sim 3$ from $\mathrm{C} 1$ to $\mathrm{C} 2$. Although the annual profiles look well mixed in $\mathrm{A} 2$ and $\mathrm{C} 2$, this is not the case seasonally. For example, BC has larger concentrations near surface during DJF but larger concentrations in upper troposphere in other seasons.

\subsection{Aerosol optical depth, direct and 1st indirect forcing}

The off-line radiative transfer model described by Penner et al. (2011) was used to calculate the aerosol optical properties and the resulting radiative forcing. Monthly averaged aerosol fields from the four cases together with the same 3-hr meteorological fields from CAM5 and AM3 were used. Consistent with the IMPACT model, there are five types of aerosol populations, pure sulfate, carbonaceous aerosols from fossil fuel (FFC), carbonaceous aerosols from biomass burning (BBC), dust, and sea salt, which are externally mixed. However, within each aerosol type, a sulfate coating that is internally mixed is included. The size distribution of pure sulfate is calculated according to the predicted mass and number while the other four types of aerosols use the prescribed size distribution that is specified in the IMPACT model. The refractive indices of sulfate, dust, and sea salt are the same as those used in Liu et al. (2007). The refractive index of fossil fuel BC is taken from Bond et al. (2006) and this is assumed to be internally mixed with fossil fuel OM. The choice of refractive index of fossil fuel/biofuel OM is not straightforward since part of this OM may be polymerized and/or oxidized and have absorption characteristics of humic-like substances (HULIS) (Sun et al., 2007; Cappa et al., 2011). Since the fraction of this material that is absorbing is not known with any precision, we made the expedient assumption that $50 \%$ of fossil fuel/biofuel $\mathrm{OM}$ had the refractive index of HULIS with the rest having the same refractive index of ammonium sulfate. Biomass burning BC is treated as in Bond et al. (2006), while biomass burning OM is from Kirchstetter et al. (2004). The refractive index of each internal mixture is a volume-weighted index average of all individual aerosol constitutes including absorbed water. The cloud fields are held constant to assess the direct forcing of anthropogenic aerosols from the preindustrial condition (PI) to the present day condition (PD). For the first indirect forcing, the cloud liquid water path and cloud fraction are held constant while the cloud droplet number concentration changes when different amounts of aerosols are activated due to the different aerosol loadings.

Table 8 gives the annual mean AOD of the four cases for present day emissions. Even though $\mathrm{C} 1$ has smaller aerosol burdens of each aerosol type than does $\mathrm{A} 1, \mathrm{C} 1$ has a much larger AOD (0.126 vs. 0.087). The AOD for sulfate in $\mathrm{C} 1$ is 0.047 , more than twice the value from A1, 0.020. The relative humidity (H_clr) used for hygroscopic aerosol growth has been scaled to the cloud-free fraction of the grid box (i.e. $\mathrm{H}_{-} \mathrm{clr}=\left(\mathrm{H}-\mathrm{f} \_\right.$cld $) /\left(1-\mathrm{f}_{-}\right.$cld $)$where $\mathrm{H}$ is the grid-box averaged 

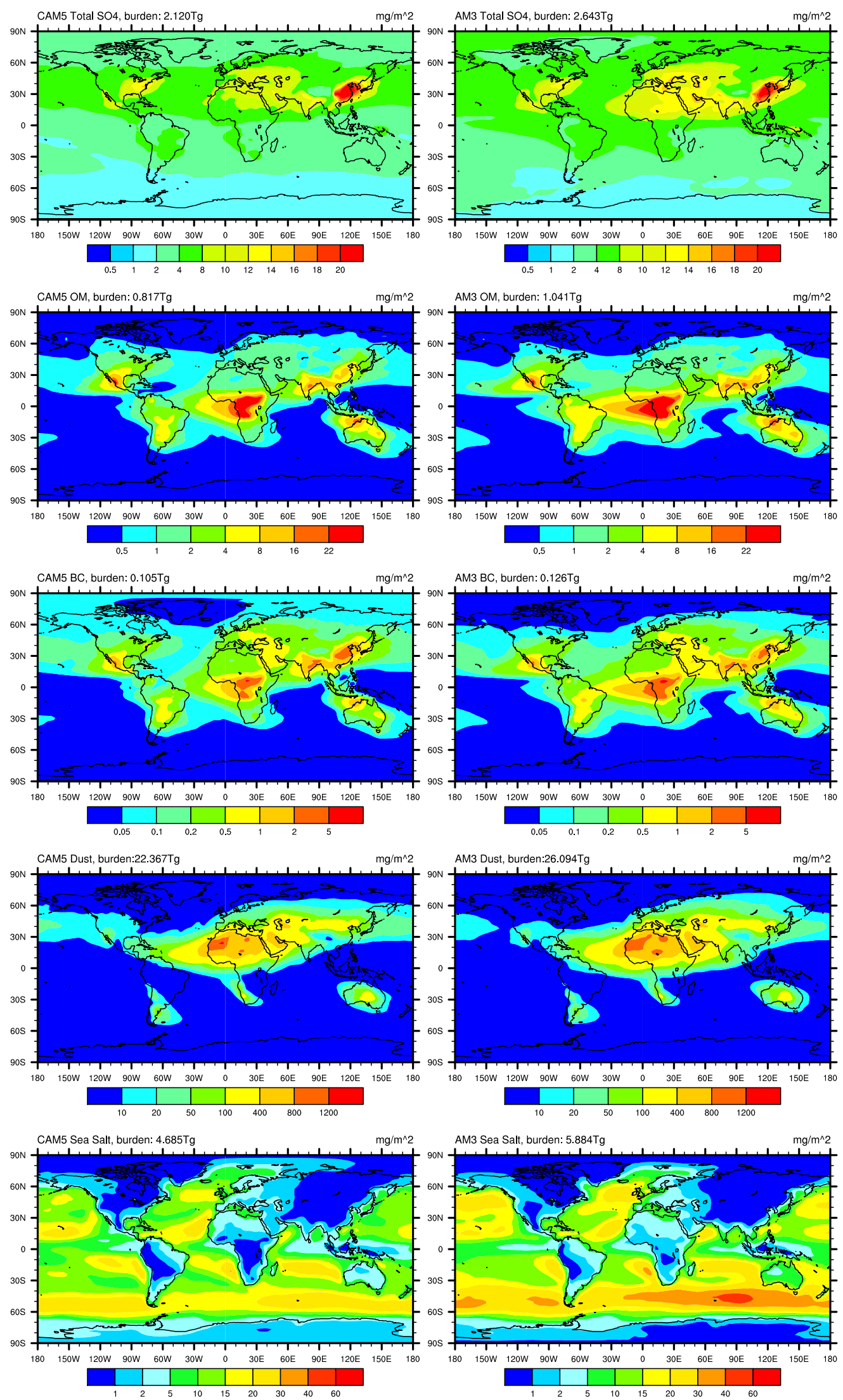

Fig. 6. Annual mean column integrated burden of sulfate, OM, BC, dust and sea salt (from top to bottom) from case C1 (left) and A1 (right). 

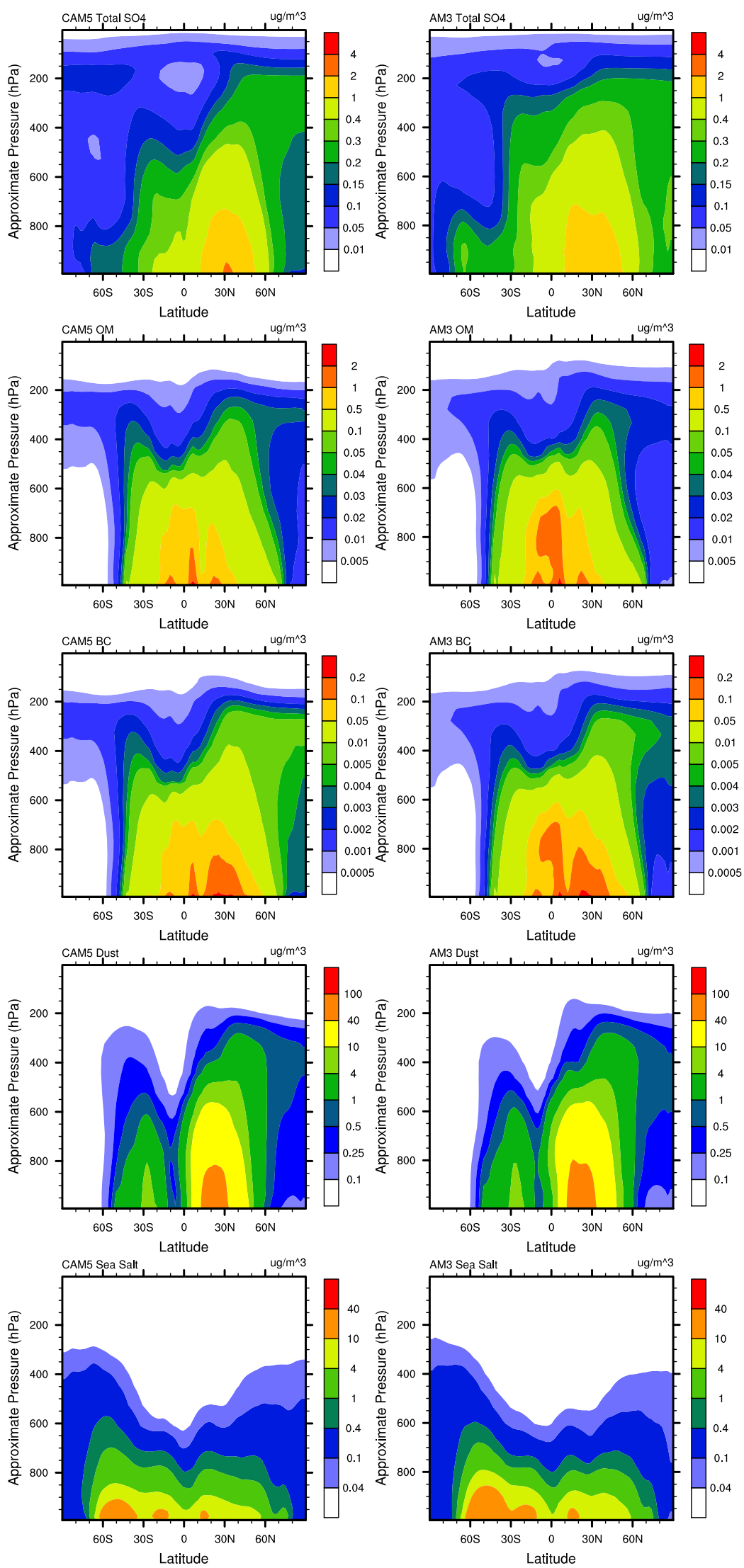

Fig. 7. Annual zonal mean concentrations of sulfate, OM, BC, dust and sea salt (from top to bottom) from case C1 (left) and A1 (right). 

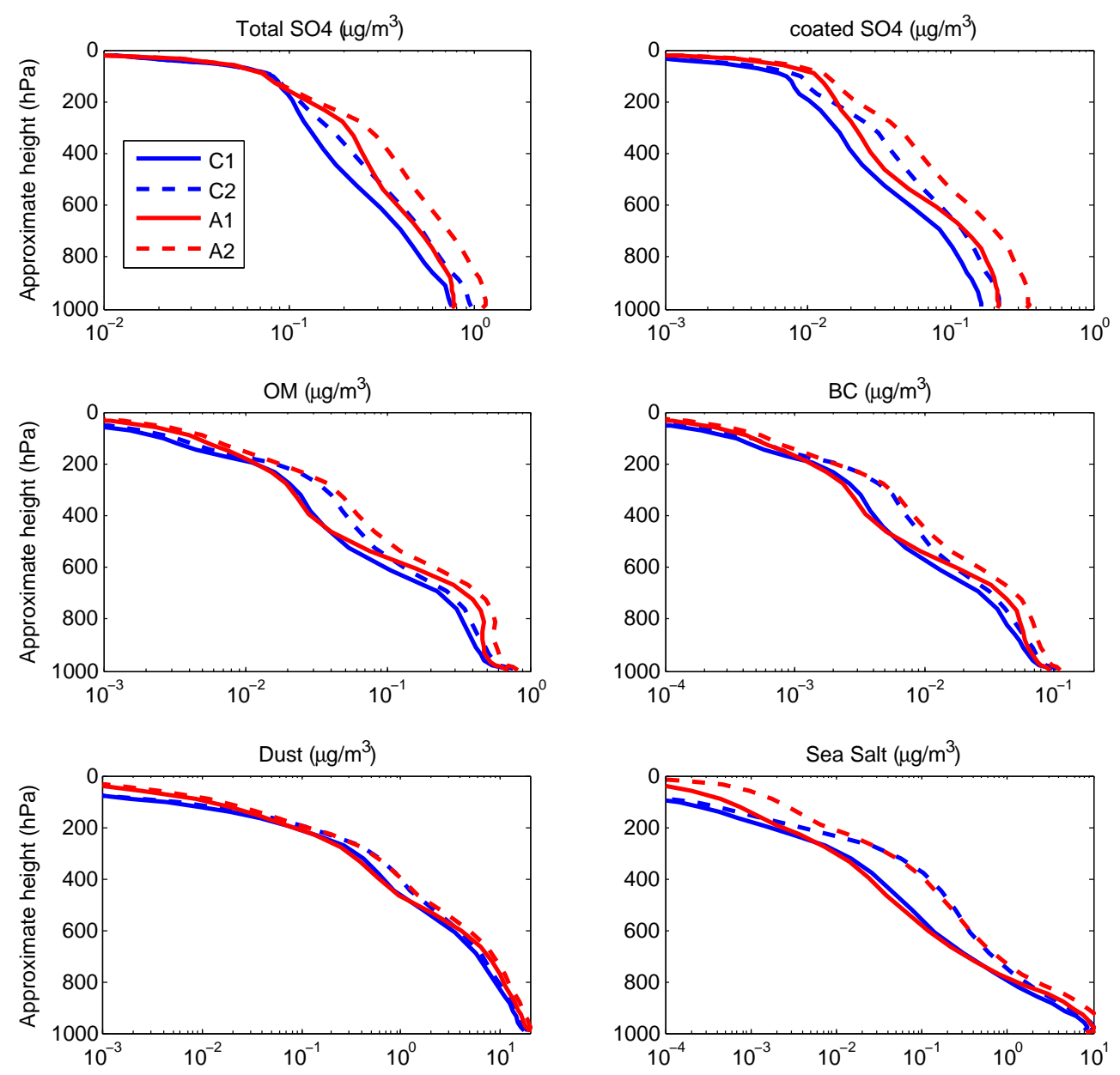

Fig. 8. Annual global mean vertical profiles of sulfate, coated sulfate, OM, BC, dust and sea salt from C1, C2, A1 and A2.

relative humidity and f_cld is the cloud fraction) and has a maximum value of $99 \%$. If we limit the maximum RH to $0 \%$, which means there is no water uptake by aerosols, then $\mathrm{C} 1$ has a smaller dry AOD than A1 (0.047 vs. 0.056) and the ratio of AOD is $0.084: 1$. When this limit is increased to $90 \%$, $\mathrm{C} 1$ still has a smaller AOD but is much closer to A1 (0.077 vs. 0.081 and $0.95: 1$ ). When the limit is set to be $99 \%, \mathrm{C} 1$ has a huge increase from 0.077 to 0.126 while A1 only increases from 0.081 to 0.087 and the ratio of AOD in the two models is $1.45: 1$. Such changes indicate the much higher frequency of occurrence of RH between $90 \%-99 \%$ in CAM5, which leads to much more water uptake by hygroscopic aerosols due to the fact that hygroscopic growth is highly nonlinear with respect to RH. From the bottom graphs of Fig. 4, we can see CAM5 has a higher relative humidity especially in middle and high latitudes.

Figure 10 shows the global distribution of the total AOD from cases $\mathrm{C} 1$ and $\mathrm{A} 1$. In dry regions including northern Africa and the Arabian Peninsula, the AOD from the two cases are comparable. However, from middle to high latitudes in both hemispheres, $\mathrm{C} 1$ has a much higher AOD. In the North Polar region, the AOD from $\mathrm{C} 1$ is almost twice as large as that from A1. This is mainly due to the more hygroscopic growth of pure sulfate in $\mathrm{C} 1$ which consists of over $70 \%$ of the total AOD in this area. When reducing the rainout/washout of aerosols by large scale precipitation in $\mathrm{C} 2$ and A2, the AOD increases from 0.127 to 0.179 in the CAM5 runs and from 0.087 to 0.122 in the AM3 runs. The comparison between $\mathrm{C} 2$ and $\mathrm{A} 2$ is very similar to that between $\mathrm{C} 1$ and $\mathrm{A} 1$.

The annual mean aerosol burdens of sulfate, black carbon and organic matter increase due to the anthropogenic emissions in going from PI to PD emissions. For example, in $\mathrm{C} 1$ pure sulfate increases from $0.26 \mathrm{Tg} \mathrm{S}$ to $0.59 \mathrm{Tg} \mathrm{S}$, organic matter increases from $0.40 \mathrm{Tg}$ to $0.82 \mathrm{Tg}$ and black carbon increases from $0.029 \mathrm{Tg}$ to $0.11 \mathrm{Tg}$; in A1 total sulfate increases from $0.32 \mathrm{Tg} \mathrm{S}$ to $0.68 \mathrm{Tg} \mathrm{S}$, organic matter increases from $0.47 \mathrm{Tg}$ to $1.04 \mathrm{Tg}$ and black carbon increases from $0.034 \mathrm{Tg}$ to $0.13 \mathrm{Tg}$. However, the burdens of dust in both cases decrease due to the increased wet scavenging efficiency as a result of more sulfate coating in PD. The burdens of sea salt almost are almost constant from PI to PD. We 

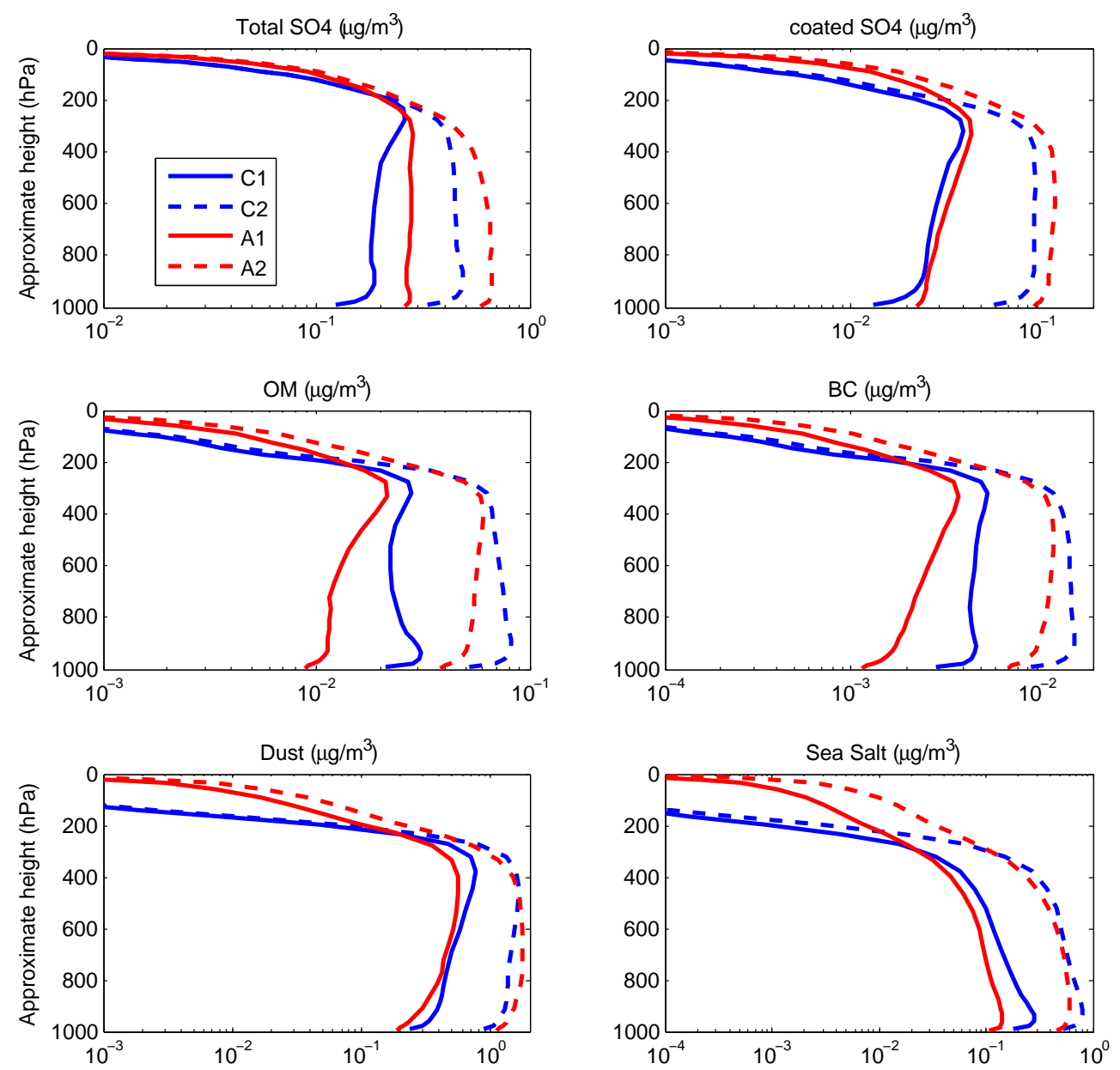

Fig. 9. Annual mean vertical profiles of sulfate, coated sulfate $\mathrm{OM}, \mathrm{BC}$, dust and sea salt in the North Polar region ( $\left.>80^{\circ} \mathrm{N}\right)$ from $\mathrm{C} 1, \mathrm{C} 2$, $\mathrm{A} 1$ and $\mathrm{A} 2$.

Table 8. Aerosol optical depth.

\begin{tabular}{lllll}
\hline Case & $\mathrm{C} 1$ & $\mathrm{C} 2$ & $\mathrm{~A} 1$ & $\mathrm{~A} 2$ \\
\hline Pure Sulfate & $0.047(37.0 \%)$ & $0.066(36.9 \%)$ & $0.020(22.7 \%)$ & $0.028(22.9 \%)$ \\
$\mathrm{FFC}+\mathrm{SO}_{4}^{*}$ & $0.006(4.8 \%)$ & $0.009(5.3 \%)$ & $0.004(4.6 \%)$ & $0.006(5.2 \%)$ \\
$\mathrm{BBC}+\mathrm{SO}_{4}^{*}$ & $0.011(8.3 \%)$ & $0.015(8.4 \%)$ & $0.008(9.4 \%)$ & $0.011(9.3 \%)$ \\
Dust $+\mathrm{SO}_{4}^{*}$ & $0.033(25.9 \%)$ & $0.039(22.0 \%)$ & $0.030(34.5 \%)$ & $0.036(29.6 \%)$ \\
Sea Salt $+\mathrm{SO}_{4}^{*}$ & $0.030(24.0 \%)$ & $0.049(27.4 \%)$ & $0.025(28.8 \%)$ & $0.040(33.1 \%)$ \\
Sum & 0.126 & 0.179 & 0.087 & 0.122
\end{tabular}

* Each type of aerosol is considered to be internally mixed with sulfate. BBC: biomass burning carbonaceous aerosols. FFC: fossil fuel burning carbonaceous aerosols.

only consider the changes of sulfate, BBC (biomass burning carbonaceous aerosol) and FFC (fossil fuel and biofuel carbonaceous aerosol) in the radiative forcing calculations and ignore the changes of dust and sea salt.

Table 9 shows the aerosol direct effect (ADE) from anthropogenic aerosols in the four cases. Although the increases of burdens of pure sulfate, BBC and FFC are larger in $\mathrm{A} 1$ from $\mathrm{PI}$ to $\mathrm{PD}, \mathrm{C} 1$ has a stronger all- sky net cooling ADE at both the TOA and the surface than A1 (TOA: $-0.48 \mathrm{~W} \mathrm{~m}^{-2}$ vs. $-0.25 \mathrm{~W} \mathrm{~m}^{-2}$, surface: $-1.13 \mathrm{~W} \mathrm{~m}^{-2}$ vs. $-0.97 \mathrm{~W} \mathrm{~m}^{-2}$ ). This is also the case for the clear-sky ADE (TOA: $-1.14 \mathrm{~W} \mathrm{~m}^{-2}$ vs. $-0.50 \mathrm{~W} \mathrm{~m}^{-2}$, surface: $-1.77 \mathrm{~W} \mathrm{~m}^{-2}$ vs. $-1.28 \mathrm{~W} \mathrm{~m}^{-2}$ ). This is mainly due to the much higher occurrence of relative humidity between $90 \% \sim 99 \%$ in CAM5 which leads to a larger AOD increase of pure sulfate from PI to PD in C1. The total AOD of C1 


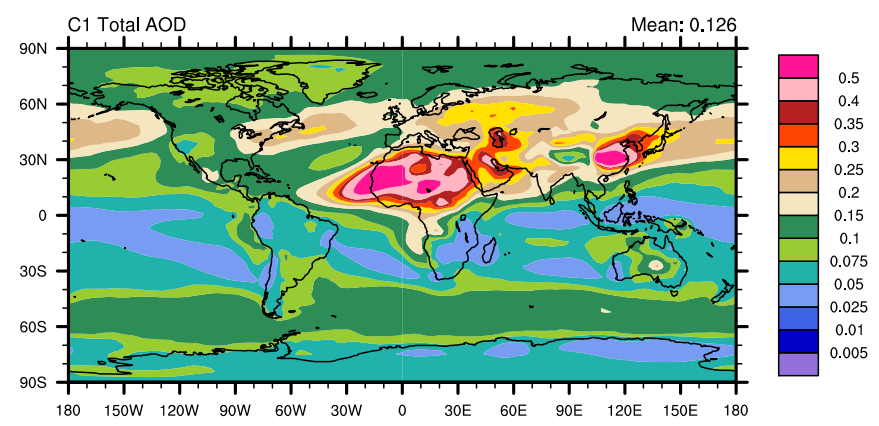

Fig. 10. Total aerosol optical depth from $\mathrm{C} 1$ (left) and A1 (right).
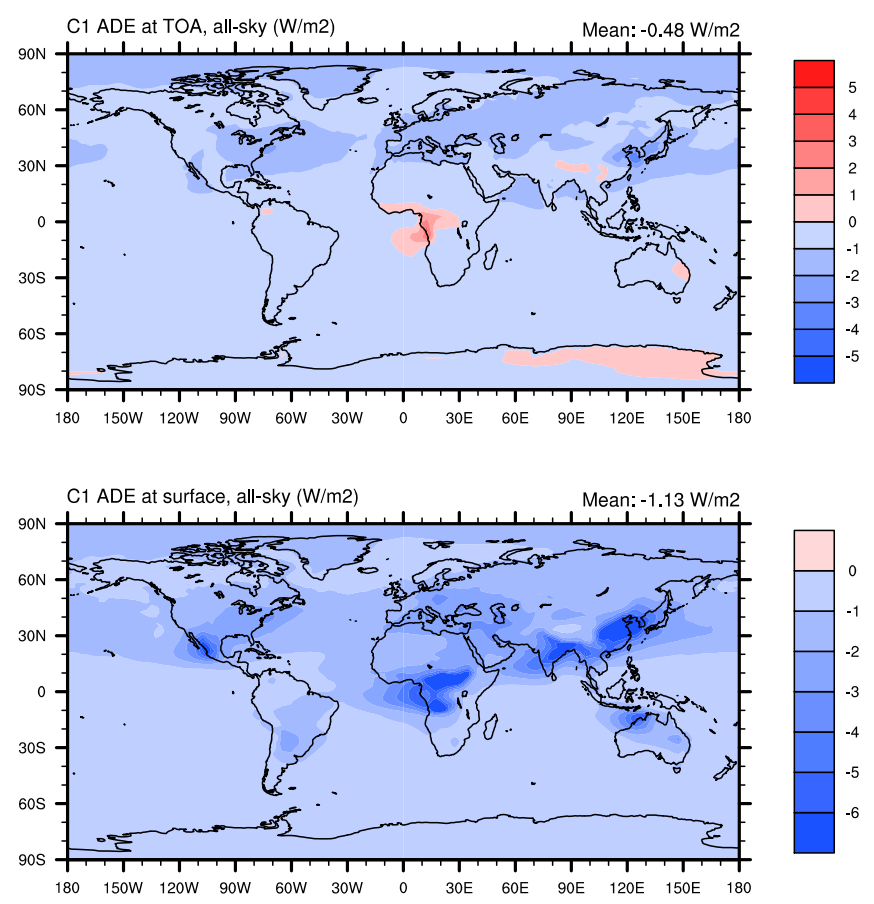
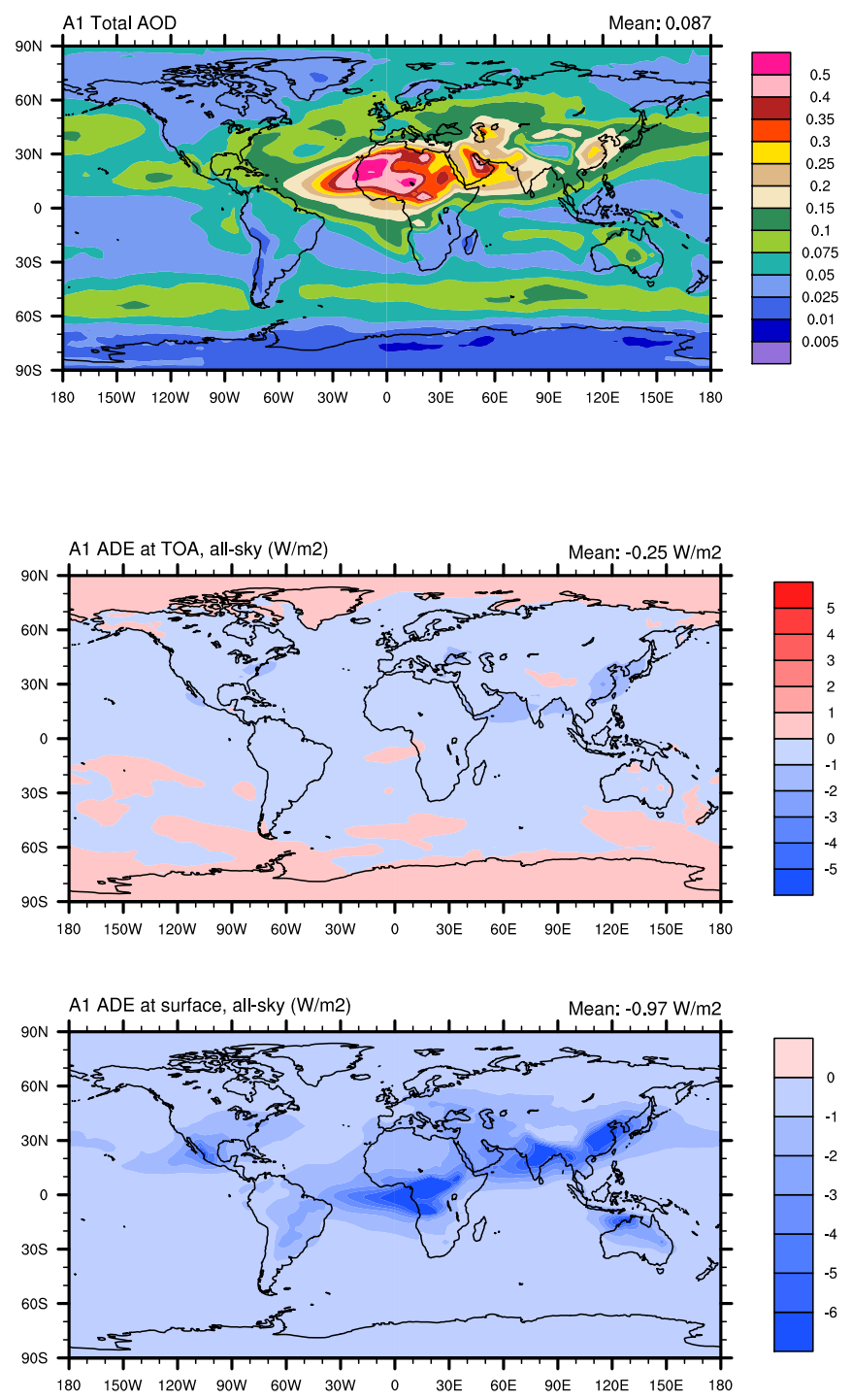

Fig. 11. All-sky direct effect at the TOA (top) and surface (bottom) in C1 (left) and A1 (right).

increases from 0.086 to 0.126 (0.0298 from sulfate, 0.0058 from BBC, 0.0046 from FFC) from PI to PD, while it only increases from 0.068 to 0.087 (0.0115 from sulfate, 0.0043 from BBC, 0.0032 from FFC) for A1. The larger increase of the AOD of pure sulfate in $\mathrm{C} 1$ (0.0298 vs. 0.0115$)$ leads to a stronger global cooling effect than A1. The absorption of radiation in $\mathrm{C} 1$ is smaller than in A1 (all-sky: $0.65 \mathrm{~W} \mathrm{~m}^{-2}$ vs. $0.72 \mathrm{~W} \mathrm{~m}^{-2}$, clear-sky: $0.64 \mathrm{~W} \mathrm{~m}^{-2}$ vs. $0.78 \mathrm{~W} \mathrm{~m}^{-2}$ ). However, this difference is smaller than the relative difference in the burdens of BBC/FFC in these two cases. This is due to the increased water uptake in $\mathrm{C} 1$ which increases the absorption of short wave radiation by the internally mixed BBC/FFC.

Figure 11 shows the global distribution of all-sky ADE at the TOA and the surface. $\mathrm{C} 1$ has a stronger cooling effect almost everywhere except in central Africa and the ocean area on its west coast. This is due to the much higher AOD in- crease of pure sulfate from PI to PD in C1. In the North Polar region, $\mathrm{C} 1$ has a net cooling effect while $\mathrm{A} 1$ has a net warming effect. There are several factors contributing to such opposite results. First, even though black carbon has net warming effect at the TOA in C1, this effect is overtaken by the strong cooling effect from the large increase of pure sulfate. Second, AM3 has much higher annual mean low cloud coverage in this area than CAM5 ( $\sim 90 \%$ vs. $\sim 70 \%$ ) (see Fig. 12 for the annual mean low cloud coverage). The larger coverage increases the absorption by black carbon and the organic matter in A1. The third possible reason is that the $\mathrm{BC}$ from $\mathrm{A} 1$ is more markedly peaked at higher altitudes than that from $\mathrm{C} 1$ (see Fig. 9). The direct forcing of BC is sensitive to the altitude of BC (Penner et al., 2003; Samset and Myhre, 2011) and can change from cooling to warming when BC is placed above clouds (Shindell and Faluvegi, 2009). 

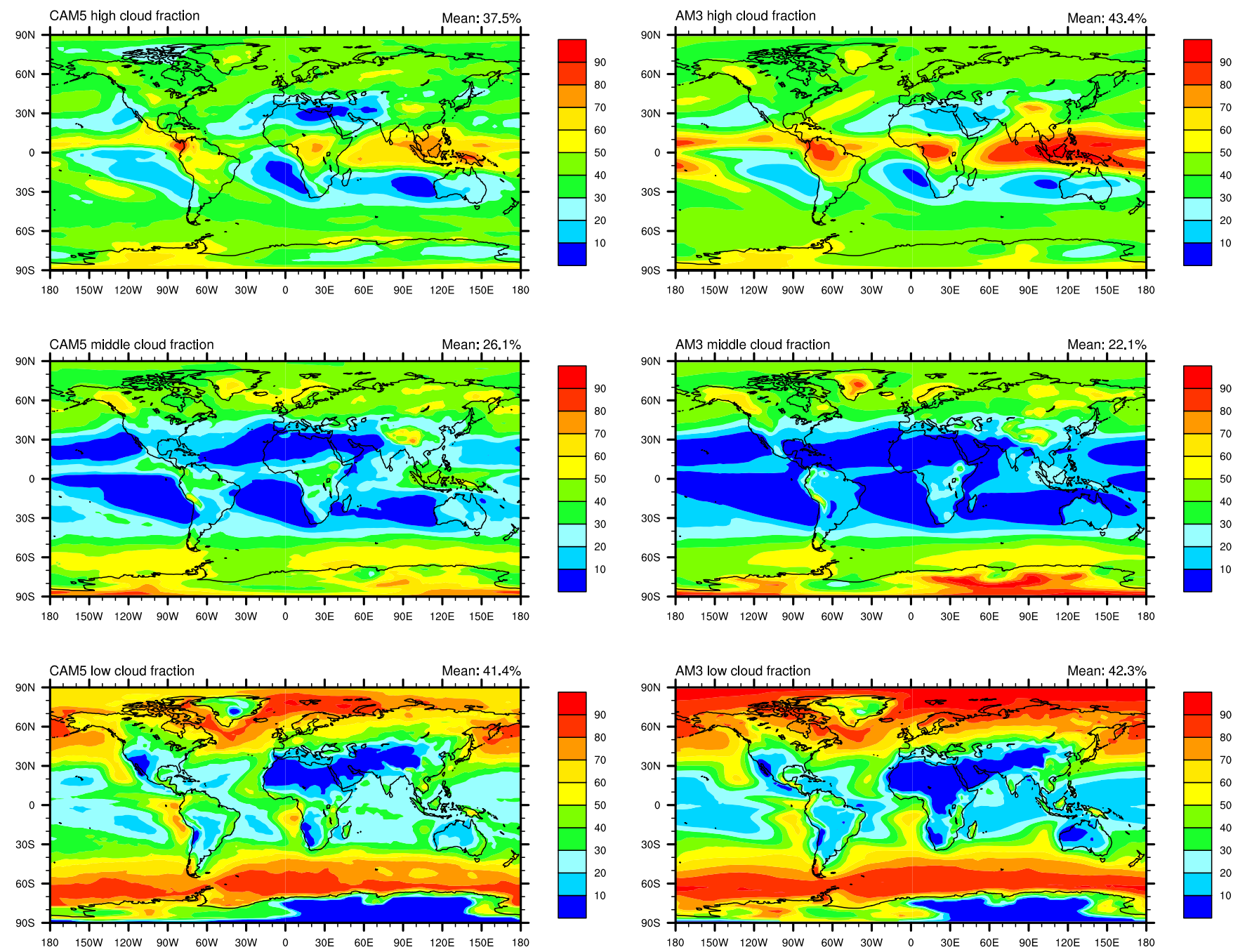

Fig. 12. Annual mean high cloud fraction ( $<440 \mathrm{hPa}$, top panel), middle cloud fraction ( 440 to $680 \mathrm{hPa}$, middle panel) and low cloud fraction ( $>680 \mathrm{hPa}$, low panel) from CAM5 (left) and AM3 (right).
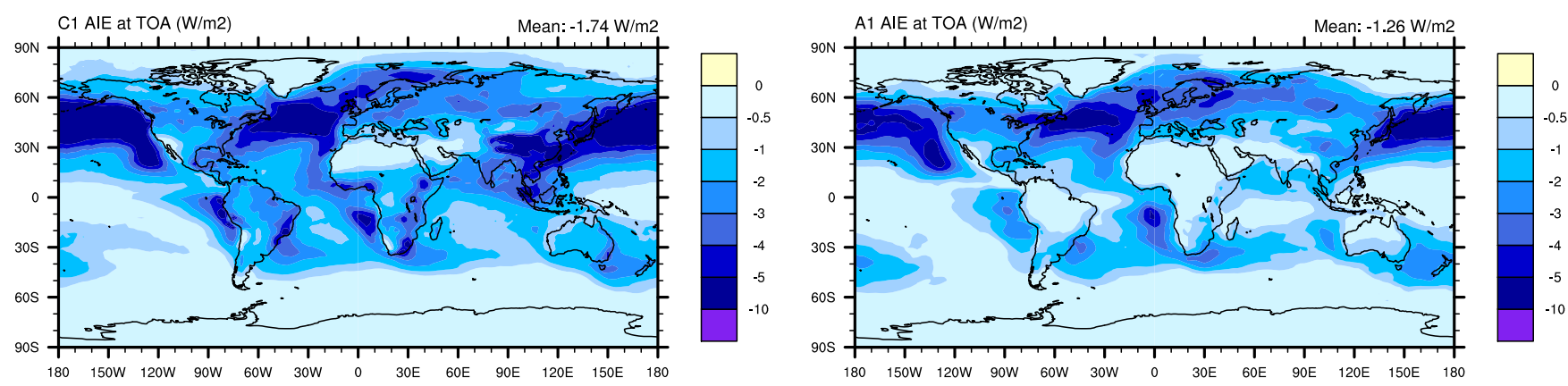

Fig. 13. First aerosol indirect effect (AIE) from case $\mathrm{C} 1$ (left) and A1 (right).

C1 has stronger net warming effect than A1 in central Africa (the largest source region for biomass burning) and the ocean area downwind to its west coast. This is partially due to the higher low cloud coverage in CAM5 than AM3 which increases the absorption by black carbon/organic matter from biomass burning in $\mathrm{C} 1$. Another possible reason for the reduced absorption in A1 in central Africa is that AM3 has larger high cloud coverage in this area which reduces the 
Table 9. Aerosol direct and $1 \mathrm{st}$ indirect forcing $\left(\mathrm{W} \mathrm{m}^{-2}\right)$.

\begin{tabular}{lllll}
\hline Case & C1 & C2 & A1 & A2 \\
\hline ADE & & & & \\
At TOA (clear-sky) & $-0.48(-1.14)$ & $-0.64(-1.47)$ & $-0.25(-0.50)$ & $-0.30(-0.69)$ \\
At surface (clear-sky) & $-1.13(-1.77)$ & $-1.45(-2.26)$ & $-0.97(-1.28)$ & $-1.32(-1.77)$ \\
Column absorption (clear-sky) & $0.65(0.64)$ & $0.81(0.79)$ & $0.72(0.78)$ & $0.98(1.08)$ \\
\hline lst AIE & & & & \\
At TOA & -1.74 & -1.77 & -1.26 & -1.44 \\
At surface & -1.65 & -1.67 & -1.23 & -1.38 \\
\hline
\end{tabular}

absorption by the black carbon/organic matter. Because of this strong shielding effect from high clouds from AM3 in this area, the all-sky atmospheric absorption is smaller than that in the clear-sky in $\mathrm{A} 1\left(0.72 \mathrm{~W} \mathrm{~m}^{-2}\right.$ vs. $\left.0.78 \mathrm{~W} \mathrm{~m}^{-2}\right)$. However, the all-sky absorption is larger than the clear-sky absorption in $\mathrm{C} 1\left(0.65 \mathrm{~W} \mathrm{~m}^{-2}\right.$ vs. $\left.0.64 \mathrm{~W} \mathrm{~m}^{-2}\right)$. This is because of the shielding effect of high clouds from CAM5 is smaller in central Africa and the absorption of BC/OM by low clouds is enhanced especially in the downwind ocean area. The patterns of the all-sky ADE at the surface from both cases are similar with strong cooling in the major industrial areas and major biomass burning source regions except that $\mathrm{C} 1$ has a stronger cooling effect from middle to high latitudes in the $\mathrm{NH}$ due to the larger AOD increases of pure sulfate. When we reduced the rainout/washout of aerosols by large scale precipitation, the all-sky $\mathrm{ADE}$ at TOA changes from $-0.48 \mathrm{~W} \mathrm{~m}^{-2}$ to $-0.64 \mathrm{~W} \mathrm{~m}^{-2}$ from $\mathrm{C} 1$ to $\mathrm{C} 2$ and from $-0.25 \mathrm{~W} \mathrm{~m}^{-2}$ to $-0.30 \mathrm{~W} \mathrm{~m}^{-2}$ from $\mathrm{A} 1$ to $\mathrm{A} 2$. The comparison between $\mathrm{C} 2$ and $\mathrm{A} 2$ is very similar to that between $\mathrm{C} 1$ and A1 except that the ADE at the TOA over the Antarctic is also positive in $\mathrm{C} 2$ due to the increased black carbon loading over the highly reflective surface.

Aerosol fields calculated from the four cases are also used to calculate the cloud droplet number concentration using the cloud droplet activation parameterization of Abdul-Razzak and Ghan $(2000,2002)$. The changed droplet number concentration due to the different aerosol loadings from PI to PD changes the cloud droplet effective radius thus the cloud albedo (defined as the first aerosol indirect forcing). A detailed description of the radiation model can be found in Wang and Penner (2009). Table 9 shows the global annual average anthropogenic 1st aerosol indirect effect (AIE) from four cases. The 1 st AIE is $-1.74 \mathrm{~W} \mathrm{~m}^{-2}$ at the TOA and $-1.65 \mathrm{~W} \mathrm{~m}^{-2}$ at the surface in $\mathrm{C} 1$ and $-1.26 \mathrm{~W} \mathrm{~m}^{-2}$ at TOA and $-1.23 \mathrm{~W} \mathrm{~m}^{-2}$ at the surface in $\mathrm{A} 1$. This calculation does not include any direct forcing effects from the aerosols. We note that in this model the increased reflectivity of clouds by the 1st AIE increases the atmospheric absorption of water vapor, $\mathrm{O}_{3}, \mathrm{O}_{2}$, and $\mathrm{CO}_{2}$ above clouds but decreases it below clouds. The net result depends on the height of the clouds, and, in both the $\mathrm{C} 1$ and $\mathrm{A} 1$ models, the 1st aerosol indirect effect causes atmospheric absorption to decrease, so that the surface AIE is somewhat smaller than that at the TOA.

Figure 13 shows the global distribution of the 1st AIE at TOA from $\mathrm{C} 1$ and A1. Since the distributions of the 1st AIE at the surface highly resemble the 1st AIE at the TOA, they are not shown here. From Fig. 13, we can see the major cooling regions include the downwind regions of the industrial regions in middle latitudes and the west coast regions of continents in the tropical and subtropical regions. Even though the increases of anthropogenic aerosols are smaller in $\mathrm{C} 1$ than those in $\mathrm{A} 1, \mathrm{C} 1$ has a stronger 1st AIE due to several reasons. First, as can been seen from Fig. 12, CAM5 has more low cloud and middle cloud coverage in the tropical regions, like the tropical Pacific Ocean, west coast of south America, tropical Indian Ocean and Indonesian, while AM3 has more high cloud coverage in these regions. In our radiative model, the activated aerosols which act as $\mathrm{CCN}$ only change the cloud droplet number concentration of warm clouds which are mainly low clouds and part of the middle clouds. So more low and middle clouds can lead to a larger 1st AIE while more high clouds over low or middle clouds can actually reduce the 1st AIE. Second, most of the cloud droplet number concentration increase comes from the activation of pure sulfate in the accumulation mode. From PI to PD, pure sulfate in the accumulation mode increases from $0.26 \mathrm{Tg} \mathrm{S}$ to $0.59 \mathrm{Tg} \mathrm{S}$ (129\% increase) in $\mathrm{C} 1$ and from $0.32 \mathrm{Tg}$ to $0.68 \mathrm{Tg}(115 \%$ increase) in A1. The global mean cloud droplet radius at the cloud top is reduced from 10.1 micron to 9.05 micron from PI to $\mathrm{PD}$ in $\mathrm{C} 1$ and from 9.76 micron to 8.82 micron in A1. As the cloud optical depth is inversely proportional to the cloud droplet radius, the relative increase of cloud optical depth is actually larger in $\mathrm{C} 1$. In the storm track regions in the $\mathrm{NH}, \mathrm{C} 1$ also has a higher 1st AIE. The cloud optical depth (COD) in the PI A1 run is larger than that in $\mathrm{C} 1$ (figures are not shown here but can be deduced from the LWP in Fig. 5) and is already highly reflective. Even though the absolute increase of COD is larger in A1 from PI to PD than in $\mathrm{C} 1$, its contribution to the increase in cloud albedo is less than that in $\mathrm{C} 1$. When we reduce the rainout/washout of aerosols by large scale precipitation, the $1 \mathrm{st}$ AIE at TOA changes from $-1.74 \mathrm{~W} \mathrm{~m}^{-2}$ to $-1.77 \mathrm{~W} \mathrm{~m}^{-2}$ from $\mathrm{C} 1$ to $\mathrm{C} 2$ and from $-1.26 \mathrm{~W} \mathrm{~m}^{-2}$ to $-1.44 \mathrm{~W} \mathrm{~m}^{-2}$ from $\mathrm{A} 1$ to $\mathrm{A} 2$. 


\section{Summary and discussion}

We used a single aerosol model, the University of Michigan IMPACT model, to explore the effects of differing meteorological fields from the NCAR CAM5 and GFDL AM3 models. We predicted the global distributions of sulfate, black carbon, organic matter, dust and sea salt, aerosol optical depth, and anthropogenic aerosol direct and 1st indirect effects.

Over all, the IMPACT-AM3 model predicts larger burdens and longer aerosol lifetimes than the IMPACT-CAM5 model. However, the IMPACT-CAM5 simulations transport more black carbon to polar regions and more dust from Asia towards North America. These differences can be attributed to differences in the vertical cloud mass flux and large-scale precipitation fields which together determine wet scavenging and rainout/washout of aerosols. The zonally averaged cloud mass flux from CAM5 is larger than that from AM3 which leads to more wet scavenging of aerosols in convective updrafts. Because wet scavenging in convective updrafts accounts for more than half of the total wet deposition, the cloud mass flux plays a dominant role in determining the aerosol burden and lifetime. Since the large-scale precipitation from AM3 is larger than that from CAM5 especially over the middle latitudes, more black carbon is rained out/washed out as it is transported to the polar regions and more dust is rained out/washed out as it is transported across the Pacific Ocean. Another important contributing factor is there is more sulfate produced in aqueous phase reactions in the IMPACT-AM3 model and therefore more sulfate coated on nonsulfate aerosols. This increased sulfate coating increases the wet scavenging efficiency of nonsulfate aerosols.

The burden, lifetime, and global distribution are also strongly affected by choice of the parameters used in the wet deposition process. A sensitivity test, in which the condensed water content was tripled, has shown that the burden and lifetime can be increased up to $\sim 20 \%$ for IMPACTCAM5 and up to $\sim 30 \%$ for IMPACT-AM3, while the black carbon in polar regions increases by a factor of four. The predicted black carbon from the IMPACT-AM3 simulations is more sensitive to this change because the AM3 model has more large-scale precipitation and also more sulfate coated on other aerosol types which is caused by a larger aqueous production. The sensitivity shown here suggests that different models may simulate very different aerosol fields even with the same aerosol module implemented in them. However, one may bring them much closer to each other by tuning the parameters used in the wet deposition process if there are good constraints available.

The total aerosol optical depth (AOD) at 550nm ranges from 0.126 to 0.179 for the IMPACT-CAM5 model and from 0.087 to 0.122 for the IMPACT-AM3 model. Even though IMPACT-AM3 model has larger aerosol burdens, it has a smaller AOD since the occurrence of relative humidity over $90 \%$ from AM3 is less frequent than that from
CAM5, which leads to less water uptake by the aerosols. The corresponding global annual average anthropogenic all-sky aerosol direct radiative forcing at the top of the atmosphere ranges from $-0.48 \mathrm{~W} \mathrm{~m}^{-2}$ to $-0.64 \mathrm{~W} \mathrm{~m}^{-2}$ for the IMPACTCAM5 runs and from $-0.25 \mathrm{~W} \mathrm{~m}^{-2}$ to $-0.30 \mathrm{~W} \mathrm{~m}^{-2}$ for the IMPACT-AM3 runs. Low clouds play an important role in increasing the absorption by $\mathrm{BC} / \mathrm{OM}$. AM3 has a higher low cloud coverage at high latitudes which leads to a positive ADE at TOA in the North Polar region while CAM5 has higher low cloud coverage to the west coast of equatorial Africa which leads to a positive ADE at TOA. The 1st aerosol indirect effect from the IMPACT-CAM5 model $\left(-1.74 \mathrm{~W} \mathrm{~m}^{-2}\right.$ to $\left.-1.77 \mathrm{~W} \mathrm{~m}^{-2}\right)$ is also larger than that from the IMPACT-AM3 model $\left(-1.26 \mathrm{~W} \mathrm{~m}^{-2}\right.$ to $\left.-1.44 \mathrm{~W} \mathrm{~m}^{-2}\right)$ by $\sim 30 \%$. This is mainly due to the higher low and middle level cloud fractions in tropical and subtropical regions from CAM5 as well as the relatively larger increases in the cloud optical depth from PI to PD. However, uncertainties in aerosol emissions (present-day and pre-industrial), absorption, interannual variability and other indirect effects are likely to dwarf these differences. For example, Forster et al. (2007) estimated the first indirect aerosol effect has a median value of $-0.7 \mathrm{~W} \mathrm{~m}^{-2}$ but with a 5 to $95 \%$ range of -0.3 to $-1.8 \mathrm{~W} \mathrm{~m}^{-2}$. This range is much larger than the range estimated for a single model and for the range from the two models. Nevertheless, it is still important to quantify the role that meteorological differences by themselves play in different model results. Also, we find that the indirect forcing for a given set of meteorology is relatively more stable than the aerosol burdens and ADE to the wet deposition treatment. One reason is the nonlinear nature of AIE (AIE is not proportional to the changes in the aerosol loadings and also depends on the PI aerosol loading) although other compensating impacts on different aspects of the aerosol distributions cannot be excluded.

Even though we only ran two years for each case, we compared the meteorological variables (e.g., convective mass flux, large-scale precipitation, in-cloud water content, cloud fields, relative humidity, etc.) that determine the differences in the simulated results from five consecutive years of data from CAM5 and AM3 and this comparison shows that the major differences identified here for the 2 year runs still hold. Thus, we believe that the simulated aerosol differences between the two models are robust, though interannual variability may diminish these differences to a slight extent. One of the major factors causing the smaller burdens and shorter lifetimes of aerosols from simulations using the CAM5 meteorological fields is that the convective cloud mass flux from CAM5 is larger than that from AM3. In IMPACT, in order to prevent soluble tracers from being transported to the top of the convective updrafts and then dispersed on the grid scale, scavenging is applied within the convective mass transport algorithm. So stronger convective mass fluxes leads to stronger vertical transport as well as larger wet scavenging. However, not all convective 
cloud mass flux, especially the mass flux from shallow convection, lead to convective precipitation. If we compare the convective precipitation from AM3 and CAM5, they are actually quite close $\left(1.91 \mathrm{~mm} \mathrm{day}^{-1}\right.$ from AM3 versus $2.08 \mathrm{~mm} \mathrm{day}^{-1}$ from CAM5). So one improvement to the wet scavenging scheme in IMPACT in convective updrafts would be to relate it to the predicted convective precipitation. Nevertheless, many of the differences in aerosol burdens and radiative effects seen in our study would also be present in the base-line models, when run with similar aerosol treatments. Our study shows that current climate models that are compared in CMIP studies still suffer from differences that may be largely removed if more detailed analysis and comparison with observations were made.

As we can see, the major discrepancies between CAM5 and AM3 results were primarily attributed to components of the atmospheric hydrological cycle (precipitation, vertical cloud mass flux, and RH). Today, there is a large emphasis on determining aerosol affects and their interactions with clouds and precipitation. However, our study highlights that as long as the hydrological cycles simulated by different GCMs do not converge, the aerosol fields, direct effects, and aerosol indirect effects will differ due to this factor alone. Thus, at least as much effort should be put into examining this aspect of GCMs as on examining aerosol indirect effects.

\section{Supplementary material related to this article is available online at: http://www.atmos-chem-phys.net/12/ 9629/2012/acp-12-9629-2012-supplement.pdf.}

Acknowledgements. This work was funded in by NSF project number AGS-0946739. Computer time was provided by the NCAR CISL facility. The authors thank Minghuai Wang and Hongyu Liu for their helpful discussion.

Edited by: P. Stier

\section{References}

Abdul-Razzak, H. and Ghan, S. J.: A parameterization of aerosol activation 2. Multiple aerosol types, J. Geophys. Res., 105, 68376844, 2000.

Abdul-Razzak, H. and Ghan, S. J.: A parameterization of aerosol activation - 3. Sectional representa ion, J. Geophys. Res., 107, 4026, doi:10.1029/2001JD000483, 2002.

Andres, R. J. and Kasgnoc, A. D.: A time-averaged inventory of subaerial volcanic sulfur emissions, J. Geophys. Res., 103, 25251-25261, 1998.

Anderson, J. L., Balaji, V., Broccoli, A. J., Cooke, W. F., Delworth, T. L., Dixon, K. W., Donner, L. J., Dunne, K. A., Freidenreich, S. M., Garner, S. T., Gudgel, R. G., Gordon, C. T., Held, I. M., Hemler, R. S., Horowitz, L. W., Klein,S. A., Knutson,T. R., Kushner, P. J., Langenhost, A. R., Lau, N.-C., Liang, Z., Malyshev, S.
L., Milly, P. C. D., Nath, M. J., Ploshay, J. J., Ramaswamy, V., Schwarzkopf, M. D., Shevliakova, E., Sirutis, J. J., Soden, B. J., Stern, W. F., Thompson, L. A., Wilson, R. J., Wittenberg, A. T., and Wyman, B. L.: The new GFDL global atmosphere and land model AM2/LM2: Evaluation with prescribed SST simulations, J. Climate, 17, 4641-4673, 2004.

Balkanski, Y., Jacob, D. J., and Gardner, G. M.: Transport and Residence Times of Tropospheric Aerosols Inferred from a Global Three-Dimensional Simulation of 210 Pb, J. Geophys. Res., 98, 20573-20586, 1993.

Bond, T. C., Habib G., and Bergstrom R. W.: Limitations in the enhancement of visible light absorption due to mixing state, J. Geophys. Res., 111, D20211, doi:10.1029/2006JD007315, 2006.

Bower, K. N., Choularton, T. W., Latham, J., Nelson, J., Baker, M. B., and Jensen, J.: A parameterization of warm clouds for use in atmospheric general circulation models, J. Atmos. Sci., 51, 2722-2732, 1994.

Bretherton, C. S. and Park, S.: A new moist turbulence parameterization in the Community Atmosphere Model, J. Climate, 22, 3422-3448, 2009.

Cappa, C. D., Che, D. L., Kessler, S. H., Kroll, J. H., and Wilson, K. R.: Variations in organic aerosol optical and hygroscopic properties upon heterogeneous OH oxidation, J. Geophys. Res., 116, D15204, doi:10.1029/2011JD015918, 2011.

Donner, L. J., Wyman, B. L., Hemler, R. S., Horowitz, L. W., Ming, Y., Zhao, M., Golaz, J.-C., Ginoux, P., Lin, S.-J., Schwarzkopf, M. D., Austin, J., Alaka, G., Cooke, W. F., Delworth, T. L., Freidenreich, S. M., Gordon, C. T., Griffies, S. M., Held, I. M., Hurlin, W. J., Klein, S. A., Knutson, T. R., Langenhorst, A. R., Lee, H.-C., Lin, Y., Magi, B. I., Malyshev, S. L., Milly, P. C. D., Naik, V., Nath, M. J., Pincus, R., Ploshay, J. J., Ramaswamy, V., Seman, C. J., Shevliakova, E., Sirutis, J. J., Stern, W. F., Stouffer, R. J., Wilson, R. J., Winton, M., Wittenberg, A. T., and Zeng, F.: The Dynamical Core, Physical Parameterizations, and Basic Simulation Characteristics of the Atmospheric Component AM3 of the GFDL Global Coupled Model CM3, J. Climate, 24, 34843519, 2011.

Ginoux, P., Chin, M., Tegen, I., Prospero, J. M., Holben, B., Dubovik, O., and Lin, S. J.: Sources and distributions of dust aerosols simulated with the gocart model, J. Geophys. Res., 106, 20255-20273, 2001.

Giorgi, F. and Chameides, W. L.: Rainout lifetimes of highly soluble aerosols and gases as inferred from simulations with a general circulation model, J. Geophys. Res., 91, 14367-14376, 1986.

Ito, A. and Penner, J. E.: Historical emissions of carbonaceous aerosols from biomass and fossil fuel burning for the period 1870-2000, Global Biogeochem. Cy., 19, GB2028, doi:10.1029/2004GB002374, 2005.

Kettle, A. J. and Andreae, M. O.: Flux of dimethylsulfide from the oceans: A comparison of updated data seas and flux models, J. Geophys. Res., 105, 26793-26808, 2000.

Kinne, S., Schulz, M., Textor, C., Guibert, S., Balkanski, Y., Bauer, S. E., Berntsen, T., Berglen, T. F., Boucher, O., Chin, M., Collins, W., Dentener, F., Diehl, T., Easter, R., Feichter, J., Fillmore, D., Ghan, S., Ginoux, P., Gong, S., Grini, A., Hendricks, J., Herzog, M., Horowitz, L., Isaksen, I., Iversen, T., Kirkev g, A., Kloster, S., Koch, D., Kristjansson, J. E., Krol, M., Lauer, A., Lamarque, J. F., Lesins, G., Liu, X., Lohmann, U., Montanaro, V., Myhre, G., Penner, J., Pitari, G., Reddy, S., Seland, Ø., Stier, P., Take- 
mura, T., and Tie, X.: An AeroCom initial assessment - optical properties in aerosol component modules of global models, Atmos. Chem. Phys., 6, 1815-1834, doi:10.5194/acp-6-1815-2006, 2006.

Kirchstetter, T. W., Novakov, T., and Hobbs, P. V.: Evidence that the spectral dependence of light absorption by aerosols is affected by organic carbon, J. Geophys. Res.-Atmos., 109, D21208, doi:10.1029/2004JD004999, 2004.

Liu, H., Jacob, D. J., Bey, I., and Yantosca, R. M.: Constraints from $210 \mathrm{~Pb}$ and $7 \mathrm{Be}$ on wet deposition and transport in a global threedimensional chemical tracer model driven by assimilated meteorological fields, J. Geophys. Res., 106, 12109-12128, 2001.

Liu, X., Penner, J. E., Das, B., Bergmann, D., Rodriguez, J. M., Strahan, S., Wang, M., and Feng, Y.: Uncertainties in global aerosol simulations: Assessment using three meteorological datasets, J. Geophys. Res., 112, D11212, doi:10.1029/2006JD008216, 2007.

Liu, X., Easter, R. C., Ghan, S. J., Zaveri, R., Rasch, P., Shi, X., Lamarque, J.-F., Gettelman, A., Morrison, H., Vitt, F., Conley, A., Park, S., Neale, R., Hannay, C., Ekman, A. M. L., Hess, P., Mahowald, N., Collins, W., Iacono, M. J., Bretherton, C. S., Flanner, M. G., and Mitchell, D.: Toward a minimal representation of aerosols in climate models: description and evaluation in the Community Atmosphere Model CAM5, Geosci. Model Dev., 5, 709-739, doi:10.5194/gmd-5-709-2012, 2012.

Liu, X. H., Penner, J. E., and Herzog, M.: Global modeling of aerosol dynamics: Model description, evaluation, and interactions between sulfate and nonsulfate aerosols, J. Geophys. Res., 110, D18206, doi:10.1029/2004JD005674, 2005.

Mari, C., Jacob, D. J., and Bechtold, P.: Transport and scavenging of soluble gases in a deep convective cloud, J. Geophys. Res., 105, 22255-22268, 2000.

Martensson, E., Nilsson, E., Leeuw, G., Cohen, L., and Hansson, H.: Laboratory simulations and parameterization of the primary marine aerosol production, J. Geophys. Res.-Atmos., 108, 4297, doi:10.1029/2002JD002263, 2003.

Monahan, E. C., Spiel, D. E., and Davidson, K. L.: A model of marine aerosol generation via whitecaps and wave disruption, in: Oceanic Whitecaps and Their Role in Air-Sea Exchange, edited by: Monahan, E. C., Spiel, D. E., and Davidson, K. L., D. Reidel, 167-174, 1986.

Penner, J. E., Andreae, M., Annegarn, H., Barrie, L., Feichter, J., Hegg, D., Jayaraman, A., Leaitch, R., Murphy, D., Nganga, J., Pitari, G., Ackerman, A., Adams, P., Austin, P., Boers, R., Boucher, O., Chin, M., Chuang, C., Collins, B., Cooke, W., DeMott, P., Feng, Y., Fischer, H., Fung, I., Ghan, S., Ginoux, P., Gong, S.-L., Guenther, A., Herzog, M., Higurashi, A., Kaufman, Y., Kettle, A., Kiehl, J., Koch, D., Lammel, G., Land, C., Lohmann, U., Madronich, S., Mancini, E., Mishchenko, M., Nakajima, T., Quinn, P., Rasch, P., Roberts, D. L., Savoie, D., Schwartz, S., Seinfeld, J., Soden, B., Tanré, D., Taylor, K., Tegen, I., Tie, X., Vali, G., Van Dingenen, R., van Weele, M., and Zhang, Y.: Aerosols, their Direct and Indirect Effects, in: Climate Change 2001: The Scientific Basis, Contribution of Working Group I to the Third Assessment Report of the Intergovernmental Panel on Climate Change (IPCC), Chapter 5, edited by: Houghton, J. T., Ding, Y., Griggs, D. J., Noguer, M., Linden, P. J. v. d., and Xiaosu, D., Cambridge University Press, Cambridge, 289-348, 2001.
Penner, J. E., Zhang, S. Y., Chin, M., Chuang, C. C., Feichter, J., Feng, Y., Geogdzhayev, I. V., Ginoux, P., Herzog, M., Higurashi, A., Koch, D., Land, C., Lohmann, U., Mishchenko, M., Nakajima, T., Pitari, G., Soden, B., Tegen, I., and Stowe, L.: A comparison of model- and satellite-derived aerosol optical depth and reflectivity, J. Atmos. Sci., 59, 441-460, 2002.

Penner, J. E., Zhang, S. Y., and Chuang, C. C.: Soot and smoke aerosol may not warm climate, J. Geophys. Res., 108, 4657, doi:10.1029/2003JD003409, 2003.

Penner, J. E., Quaas, J., Storelvmo, T., Takemura, T., Boucher, O., Guo, H., Kirkevåg, A., Kristjánsson, J. E., and Seland, Ø.: Model intercomparison of indirect aerosol effects, Atmos. Chem. Phys., 6, 3391-3405, doi:10.5194/acp-6-3391-2006, 2006.

Penner, J. E., Xu, L., and Wang, M.: Satellite methods underestimate indirect climate forcing by aerosols, Proc. Natl. Acad. Sci., 108, 13404-13408, 2011.

Samset, B. H. and Myhre, G.: Vertical dependence of black carbon, sulphate and biomass burning aerosol radiative forcing, Geophys. Res. Lett., 38, L24802, doi:10.1029/2011GL049697, 2011.

Schulz, M., Textor, C., Kinne, S., Balkanski, Y., Bauer, S., Berntsen, T., Berglen, T., Boucher, O., Dentener, F., Guibert, S., Isaksen, I. S. A., Iversen, T., Koch, D., Kirkev g, A., Liu, X., Montanaro, V., Myhre, G., Penner, J. E., Pitari, G., Reddy, S., Seland, $\varnothing$., Stier, P., and Takemura, T.: Radiative forcing by aerosols as derived from the AeroCom present-day and pre-industrial simulations, Atmos. Chem. Phys., 6, 5225-5246, doi:10.5194/acp-65225-2006, 2006.

Shindell, D. and Faluvegi, G.: Climate response to regional radiative forcing during the twentieth century, Nature Geosci., 2, 294-300, doi:10.1038/ngeo473,2009.

Shindell, D. T., Chin, M., Dentener, F., Doherty, R. M., Faluvegi, G., Fiore, A. M., Hess, P., Koch, D. M., MacKenzie, I. A., Sanderson, M. G., Schultz, M. G., Schulz, M., Stevenson, D. S., Teich, H., Textor, C., Wild, O., Bergmann, D. J., Bey, I., Bian, H., Cuvelier, C., Duncan, B. N., Folberth, G., Horowitz, L. W., Jonson, J., Kaminski, J. W., Marmer, E., Park, R., Pringle, K. J., Schroeder, S., Szopa, S., Takemura, T., Zeng, G., Keating, T. J., and Zuber, A.: A multi-model assessment of pollution transport to the Arctic, Atmos. Chem. Phys., 8, 5353-5372, doi:10.5194/acp-85353-2008, 2008.

Smith, S., Andres, R., Conception, L., and Lurz, J.: Historical sulfur dioxide emissions 1850-2000: Methods and resutls, jgcri research report pnnl 14537, Paciific Northwest National Laboratory, Richland, WA, USA, 14537, 2004.

Smith, S. J., Pitcher, H., and Wigley, T. M. L.: Global and regional anthropogenic sulfur dioxide emissions, Global Planet Change, 29, 99-119, 2001.

Sun, H., Biedermann, L., and Bond, T. C.: Color of brown carbon: A model for ultraviolet and visible light absorption by organic carbon aerosol, Geophys. Res. Lett., 34, L17813, doi:10.1029/2007GL029797,2007.

Textor, C., Schulz, M., Guibert, S., Kinne, S., Balkanski, Y., Bauer, S., Berntsen, T., Berglen, T., Boucher, O., Chin, M., Dentener, F., Diehl, T., Easter, R., Feichter, H., Fillmore, D., Ghan, S., Ginoux, P., Gong, S., Grini, A., Hendricks, J., Horowitz, L., Huang, P., Isaksen, I., Iversen, I., Kloster, S., Koch, D., Kirkev g, A., Kristjansson, J. E., Krol, M., Lauer, A., Lamarque, J. F., Liu, X., Montanaro, V., Myhre, G., Penner, J., Pitari, G., Reddy, S., Seland, Ø., Stier, P., Takemura, T., and Tie, X.: Analysis and quantifica- 
tion of the diversities of aerosol life cycles within AeroCom, Atmos. Chem. Phys., 6, 1777-1813, doi:10.5194/acp-6-1777-2006, 2006.

Textor, C., Schulz, M., Guibert, S., Kinne, S., Balkanski, Y., Bauer, S., Berntsen, T., Berglen, T., Boucher, O., Chin, M., Dentener, F., Diehl, T., Feichter, J., Fillmore, D., Ginoux, P., Gong, S., Grini, A., Hendricks, J., Horowitz, L., Huang, P., Isaksen, I. S. A., Iversen, T., Kloster, S., Koch, D., Kirkev g, A., Kristjansson, J. E., Krol, M., Lauer, A., Lamarque, J. F., Liu, X., Montanaro, V., Myhre, G., Penner, J. E., Pitari, G., Reddy, M. S., Seland, Ø., Stier, P., Takemura, T., and Tie, X.: The effect of harmonized emissions on aerosol properties in global models an AeroCom experiment, Atmos. Chem. Phys., 7, 4489-4501, doi:10.5194/acp-7-4489-2007, 2007.
Wang, M. and Penner, J. E.: Aerosol indirect forcing in a global model with particle nucleation, Atmos. Chem. Phys., 9, 239-260, doi:10.5194/acp-9-239-2009, 2009.

Wang, M., Penner, J. E., and Liu, X.: Coupled IMPACT aerosol and NCAR CAM3 model: Evaluation of predicted aerosol number and size distribution, J. Geophys. Res., 114, D06302, doi:10.1029/2008JD010459, 2009.

Zhang, K., Wan, H., Wang, B., Zhang, M., Feichter, J., and Liu, X.: Tropospheric aerosol size distributions simulated by three online global aerosol models using the M7 microphysics module, Atmos. Chem. Phys., 10, 6409-6434, doi:10.5194/acp-10-64092010, 2010. 